ISSN: 0514-7336

DOI: http://dx.doi.org/10.14201/zephyrus20157699119

\title{
ARQUEOLOGÍA DEL PAISAJE EN EL ENTORNO DE LAURO: UNA APROXIMACIÓN MICRORREGIONAL A LA CONSTRUCCIÓN DEL TERRITORIO ROMANO EN EL NORESTE DE LA PENÍNSULA IBÉRICA
}

\section{Landscape Archaeology in the surrounding of Lauro: A micro-regional approach to Roman territorial shaping in a north-eastern sector of the Iberian Peninsula}

\author{
Arnau García Molsosa, Marta Flórez Santasusana y Josep María Palet Martínez \\ Grupo de Investigación en Arqueología del Paisaje (gIAP)-Institut Català d'Arqueologia Clàssica (ICAC). Plaza Ro- \\ vellat,s/n.43003 Tarragona.Correo-e: agarcia@icac.cat; mflorez.giap@gmail.com; jpalet@icac.cat
}

Recepción: 26/11/2014; Revisión: 6/02/2015; Aceptación: 5/09/2015

BIBLID [0514-7336 (2015) LXXVI, julio-diciembre; 99-119]

Resumen: La asociación del topónimo Lauro a la historia antigua del sector oriental de la comarca del Vallès (Barcelona) es una constante en la historiografía sobre la región. En este artículo, esa Lauro históricoarqueológica sirve de guía para exponer los resultados de la investigación llevada a cabo en un pequeño sector de esta comarca que, por la complejidad del registro arqueológico, ha resultado de gran interés para estudiar la dinámica de la estructuración territorial del entorno rural en una de las primeras zonas conquistadas por Roma fuera de la península itálica.

Partiendo de las herramientas conceptuales y metodológicas de la arqueología del paisaje se han llevado a cabo campañas de prospección extensiva e intensiva del registro superficial. El material recogido y los restos estructurales documentados en estos trabajos de campo permitieron definir distintos espacios de ocupación y actividad en una cronología que comprende desde el desarrollo de las sociedades indígenas a la consolidación del Imperio Romano -ss. IV a. C.-II d. C.-.

Partiendo de estos datos se exponen varios argumentos que permiten discutir el impacto de la conquista romana en la dinámica de poblamiento a escala microrregional en un sector que puede representar un modelo para contrastar con otras áreas en futuras investigaciones.

Palabras clave: Paisajes culturales; prospecciones arqueológicas; dinámica de poblamiento; período ibérico final; período romano; Vallès Oriental.

AвsтRACT: The link between the place-name Lauro and the ancient history of the eastern part of Vallès region (Barcelona) is a constant throughout historiography. In this paper, this ancient Lauro serves as a guide to present the results of a research conducted in a small area, which due to archaeological data complexity has been of great interest to study the dynamics of territorial structuration in one of the first rural areas conquered by Rome outside the Italian peninsula.

From Landscape Archaeology conceptual and methodological tools, extensive and intensive archaeological surveys have been developed. The collected materials and the documented structural remains have allowed 
us to define settlement and human occupation in a chronology ranging from the development of indigenous (Iberian) societies to the consolidation of the Roman Empire -IVth BC-IIth AD-.

The results of these works set out the elements to analyse the impact of Roman conquest in settlement evolution at a micro-regional scale. The studied area may represent a model to contrast in other regions and to discuss in future works.

Key words: Cultural landscapes; archaeological surveys; settlement dynamics; Late Iron Age period; Roman period; Eastern Vallès.

\section{Situación y objetivos}

Los datos y reflexiones objeto de este artículo parten de un estudio llevado a cabo por un equipo del GIAP-ICAC en la zona de Samalús (Fig. 1) que ha contado con el apoyo de investigadores del ICTJA-CsIC ${ }^{1}$. El trabajo se ha llevado a cabo en una área fronteriza entre los términos municipales de Cànoves i Samalús, La Garriga y la parroquia de Llerona -municipio de Les Franqueses del Vallès-. El estudio forma parte de un trabajo más general sobre los paisajes culturales del llano y la montaña prelitorales, centrados en la actual comarca del Vallès Oriental ${ }^{2}$. Dentro de este marco más general, se seleccionaron diversos sectores concretos en los que llevar a cabo estudios de caso más detallados y realizar de forma acotada el trabajo de campo.

La zona de Samalús constituye un buen ejemplo de los paisajes de contacto entre la zona de montaña y el llano prelitoral. El paisaje tradicional de esta área se caracteriza por la presencia de amplios espacios de cultivos en terrazas y un poblamiento rural de carácter disperso o semidisperso, en la actualidad

Agradecemos la colaboración de S. Giralt, del ICTJACSIC, por la dirección de los estudios geomorfológicos en este territorio. También damos las gracias a A. Trullén por la ayuda prestada en el desarrollo de las prospecciones y estudio de los materiales.

2 Estos trabajos han dado como resultado dos tesis doctorales (Flórez, M.: Dinàmica dels assentaments i estructuració del territori a la Laietània interior: estudi del Vallès Oriental de l'època ibèrica a l'Alta Edat Mitjana, presentada en 2011 en la UAB; García, A.: Arqueologia dels paisatges culturals del massís del Montseny. Dinàmiques històriques de la prehistòria a l'edat mitjana, presentada en 2013 en URV-ICAC, Tarragona [disponible en http://hdl.handle.net/10803/290993]) y la publicación de diversos avances provisionales sobre la metodología empleada; también se han expuesto algunos resultados en distintos foros nacionales e internacionales (Flórez y Palet, 2010, 2011, 2012, 2014; García et al., 2012, 2014; Flórez et al., 2013).

(C) Universidad de Salamanca en vías de desaparición. Pese al aspecto rural que aún conserva esta zona, la agricultura mecanizada ha tenido un fuerte impacto en el territorio y ha significado la eliminación y el abandono de las terrazas más estrechas, de mayor pendiente para crear superficies de cultivo más amplias y de relieve más suave. Se trata, por tanto, de un paisaje en transformación. A pesar de todo ello, en el contexto del área metropolitana de Barcelona, es un territorio poco urbanizado, lo que permite la realización de trabajos de prospección superficial. Por otra parte, se conservan espacios agrarios en terrazas, de morfología histórica tradicional, en diversos sectores actualmente no cultivados, cubiertos de bosque.

De manera más específica, el presente trabajo se centra en la caracterización de las formas del poblamiento y en la explotación del territorio a partir del registro arqueológico superficial. Se pretende también analizar las distintas fases cronológicas detectadas con especial atención a los períodos ibérico y romano; caracterizar la red viaria y su posible relación con los diversos asentamientos rurales y su inserción en la red viaria regional; y finalmente estudiar las estructuras agrarias y conocer sus fases de configuración. En este trabajo trataremos principalmente del análisis de las dinámicas del asentamiento rural a partir de los trabajos de prospección realizados.

\section{Antecedentes y contexto histórico-arqueológico del área de estudio}

\subsection{La Lauro del Vallès y Samalús, breve estado de la cuestión}

El área de estudio se inscribe en un contexto histórico-arqueológico relacionado con el antiguo topónimo Lauro. El conocimiento de una o más realidades políticas con este nombre en la provincia romana de 


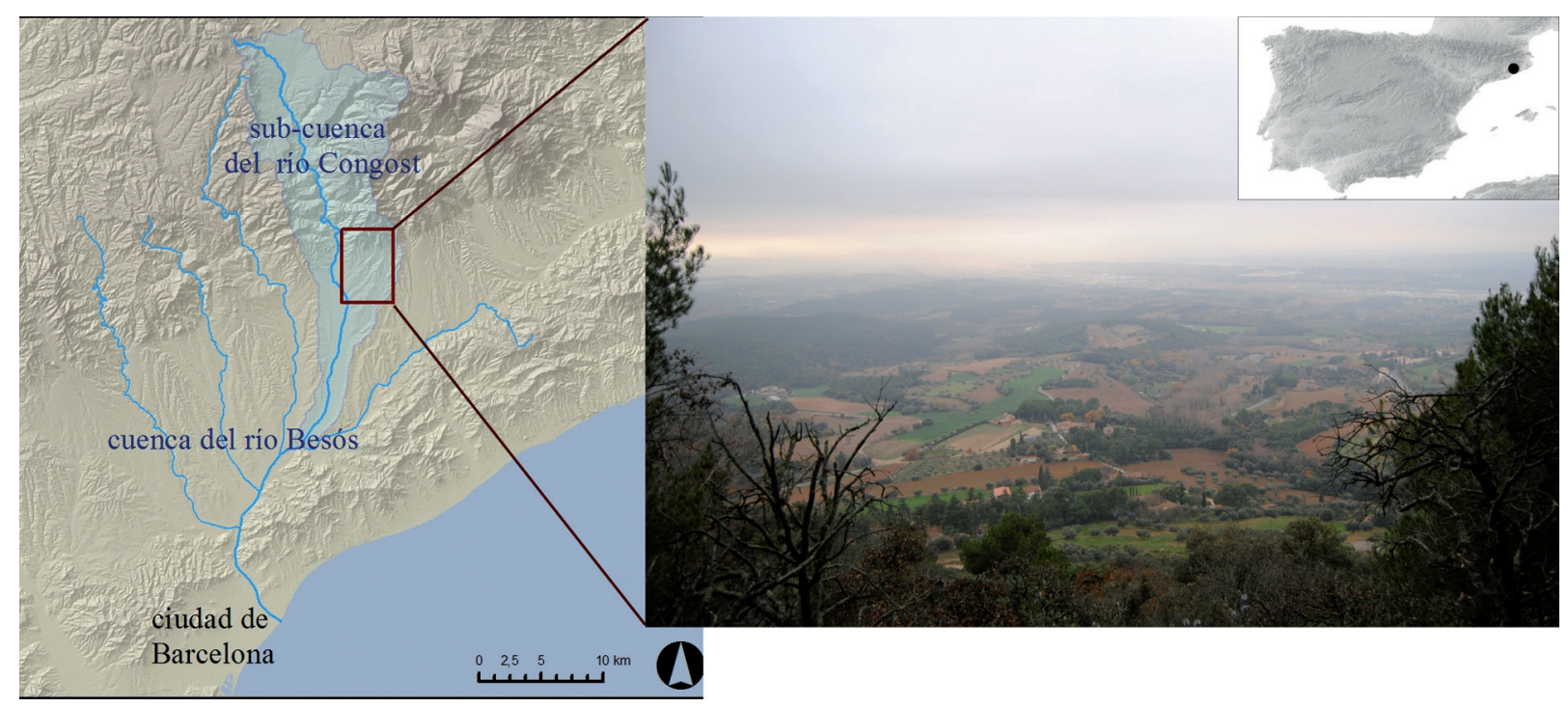

FIG. 1. Localización y panorámica del área de estudio; para la cartografía de base utilizada en las diversas figuras se ha usado un Modelo Digital de Elevaciones y una capa que muestra la hidrografia de la zona, creados a partir de los materiales del Institut Cartogràfic de Catalunya.

la Hispania Citerior ${ }^{3}$ se debe a un conjunto de fuentes literarias, epigráficas y numismáticas sobre las que existe bibliografía abundante (Balvey, 1931; Schulten, 1937: 197; Villaronga, 1960; Estrada y Villaronga, 1967; Miró, 1988; Konrad, 1994: 157; Llorens y Ripollès, 1998; Pascual, 1998; Aguilar, 2005; Padrós, 2005; Martí, 2008; Panosa, 2012: 135-151; Sinner, 2013: 178-179; Guàrdia, 2015).

Existe consenso en situar como mínimo uno de estos lugares en la actual comarca del Vallès Orien$\mathrm{tal}^{4}$, área que seguramente formaba parte de la antigua región vinculada al pueblo de los layetanos. Esta ubicación se apoya en dos aspectos principales: en primer lugar por la vinculación de esta zona a la producción de vino conocida como lauronense, fechada

3 En las fuentes latinas se usa la palabra oppidum y en las griegas polis; en ambos casos el concepto sería más político que descriptivo de un entorno urbano, aunque por los hechos narrados se puede deducir que como mínimo disponía de algún tipo de recinto fortificado.

4 Se ha mantenido la duda de si algunas fuentes literarias se podrían referir en realidad a un segundo sitio con el nombre de Lauro en la Citerior que estaría ubicado más al s, en la zona de Valencia. Hay que considerar, sin embargo, que de la lectura de los textos no tiene por qué deducirse necesariamente que los hechos mencionados tuvieran lugar al s del río Ebro y se podrían situar igualmente en la zona del Vallès (Konrad, 1994: 157). en el siglo i d. C. (Miró, 1985; Pascual, 1998; Berni, Carreras y Revilla, 1998; Aguilar, 2005). Un segundo argumento es la distribución espacial de los hallazgos de monedas con la leyenda $L A V R O$ en alfabeto ibérico, aspecto ampliamente abordado en dos trabajos recientes (Sinner, 2013: 178-179; Guàrdia, 2015). Estos dos aspectos se han reforzado con la presencia en la zona del topónimo moderno de Llerona, cuyo término aparece citado como Lauro en los primeros documentos posteriores a la conquista carolingia ${ }^{5}$.

Dentro de este marco geográfico, los trabajos más recientes han focalizado la atención en la zona de Samalús en general, y en el yacimiento de Puig Castell en particular, como posible núcleo principal de esta Lauro histórica. Esta hipótesis de trabajo ha sido formulada en trabajos recientes (Martí, 2008: 68; Panosa, 2012: 146-147; Sinner, 2013: 179) y ha sido extensamente desarrollada por parte del equipo que ha realizado las últimas excavaciones en este yacimiento (Guàrdia, 2013, 2014, 2015) ${ }^{6}$.

5 Acta de consagración de la vecina parroquia de Sant Genís de la Ametlla, fechada en el año 932 (Pladevall, 1991: 295 y 350 ).

6 Basándose en los trabajos aquí presentados, la hipótesis fue expuesta en una comunicación de un coloquio en 2012 (García et al., 2014) y recogida en una de nuestras tesis doctorales (García, A., op. cit. n. 2). 


\subsection{La investigación arqueológica en el área de estudio}

Las primeras referencias conocidas a la arqueología de la zona de Samalús provienen del entorno excursionista catalán de principios de $s$. Xx, y concretamente del antropólogo J. Batista i Roca (Gallardo, 1938: 156-157). Tras la guerra civil destaca la figura de J. Estrada (Pardo, 2002), quien tras recoger el conocimiento anterior $y$, durante casi 50 años, realiza una exhaustiva tarea de prospección y estudio arqueológico de la región. Es fundamentalmente mediante los trabajos de J. Estrada (Estrada, 1946-59, 1955, 1993; Estrada y Villaronga, 1967) como se conoce una importante densidad de poblamiento rural antiguo en la zona del Vallès Oriental, especialmente en el entorno de Llerona y pueblos limítrofes.

La fase tardorrepublicana de los ss. II-I a. C. - caracterizada por la presencia de cerámica de barniz negro campaniense y ánfora itálica, entre otros materiales- está presente en una buena parte de estos asentamientos que fueron definidos inicialmente como villas romano-republicanas o iberorromanas (Estrada, 1993: 54); sobre este concepto se ha discutido ampliamente en diversos trabajos (Járrega, 2000; Revilla, 2004; Plana y Revilla, 2009; Flórez y Palet, 2010: 153-154; Cantarellas, 2014) y, en todo caso, recoge una heterogeneidad de establecimientos poco conocidos con cronologías no siempre lo suficientemente precisas ${ }^{7}$.

Desde el Museo de Granollers se llevó a cabo a inicios de los ochenta un proyecto de investigación del territorio de las poblaciones de la Garriga, Llerona y Samalús ${ }^{8}$, en el marco del cual se realizó un estudio del yacimiento de Can Martí (Aquilué y Pardo, 1990).

A partir de los años noventa, la investigación arqueológica en la comarca ha estado muy vinculada

\footnotetext{
Debe considerarse que normalmente nos referimos a yacimientos conocidos por hallazgos de superficie o mediante excavaciones muy limitadas. En este trabajo limitaremos al máximo el uso de la palabra villa para este período y hablaremos de asentamientos rurales. Consideramos que con el tipo de datos disponibles el concepto de villa resulta más bien distorsionante. Habría que abordar esta cuestión terminológica desde un conocimiento mucho más profundo de los diversos yacimientos.

8 Aquilué, X. et al. (1982): "La romanització al Vallès Oriental. Un programa de treball”. Documento inédito depositado en el Archivo Comarcal del Vallès Oriental.
}

al desarrollo de la arqueología profesional y a la expansión de las intervenciones de urgencia, generadas por la actividad urbanística e industrial. Pese a esta multiplicación de las intervenciones en la zona, no se habían realizado actuaciones arqueológicas en Samalús hasta la puesta en marcha de las prospecciones del Giap-ICAC objeto de este trabajo (2008-2011) y de las campañas de excavación en 'Puig Castell' (2011-2014).

\section{Materiales y metodología}

La prospección arqueológica ha sido la principal herramienta de trabajo. A nivel metodológico se han realizado dos tipos de prospección en función de los objetivos y del tipo de trabajo desarrollado.

\subsection{Prospección extensiva}

El trabajo de campo ha consistido, en primer lugar, en el desarrollo de prospecciones extensivas. Este tipo de prospección se ha caracterizado por la visita selectiva de yacimientos inventariados en la carta arqueológica, a fin de comprobar y verificar sus características. Esta cuestión es básica en una zona para la cual existe un gran número de hallazgos arqueológicos de carácter y de fiabilidad diversa, recopilados a lo largo de los últimos 50 años.

Los trabajos consistieron en la localización y delimitación de los restos descritos en la carta, corrigiendo si era preciso las coordenadas del emplazamiento. Se realizó a continuación una prospección intra-site del yacimiento, de cobertura total, que comprendió también la recogida de artefactos. Los prospectores se colocaron en línea con una separación de unos $10 \mathrm{~m}$ entre ellos. Se situaron las concentraciones de determinados materiales -cerámica fina de mesa, contenedores, escorias-. Se ubicaron y cuantificaron sobre el terreno las concentraciones de material constructivo, recogiéndose solo una muestra testimonial de este tipo de material. Para delimitar el área de interés arqueológico, se prospectaron las parcelas adyacentes, extendiéndose el área hasta parcelas no prospectables o que dieron resultado negativo. 


\subsection{Prospección intensiva}

La prospección intensiva se realizó en una pequeńa sierra delimitada por dos arroyos, donde la carta arqueológica documenta diversos puntos de interés arqueológico. A continuación se asignó a cada parcela de cultivo del área un número de Unidad de Prospección [Up]. En total se prospectaron $66,37 \mathrm{ha}^{9}$, de las cuales $47,47-72 \%$ - dieron resultado positivo. Las dimensiones de la mayor parte de las parcelas son relativamente pequeńas, con tendencia a situarse hacia alrededor de $1 / 2$ ha (Fig. 2).

Cada parcela fue recorrida por el equipo de prospección mediante líneas equidistantes de unos 5 $\mathrm{m}$, distancia que significa en realidad una cobertura prácticamente total de la superfície, limitando enormemente la presencia de concentraciones de material en los espacios entre prospectores. El material arqueológico de superficie fue recogido en su totalidad, anotándose también las zonas de mayor concentración de materiales arqueológicos.

El material que presentaba características más modernas no fue recogido ${ }^{10}$. Se recogió, sin embargo, un alto porcentaje de fragmentos informes de cerámica común, la cual debe ser interpretada con prudencia en contextos de prospección, pues en su inmensa mayoría son fragmentos informes de difícil adscripción cronocultural.

Salvo alguna excepción, las parcelas prospectadas se encuentran dedicadas al cultivo de cereal. Las prospecciones fueron realizadas en otońo, período del año durante el cual se realiza el arado para la preparación de la siembra. De esta manera, las condiciones de visibilidad eran óptimas en la mayor parte del área de prospección ${ }^{11}$.

9 Esta cifra corresponde a la suma del área de las parcelas prospectadas.

10 Se recogieron, no obstante, fragmentos de cerámica vidriada moderna para ayudar a interpretar el impacto de las fases más modernas en el paisaje. Para este trabajo no hemos tenido en cuenta estos materiales ni, a nivel general, los que se clasificaron como medieval/modernos al hacer el inventario -un 4,9\% del material recogido en la prospección extensiva y un $6,5 \%$ en la intensiva-.

${ }_{11}$ Menos del 15\% del área de prospección intensiva estaba ocupada por bosque $-6,8$ ha-, cultivos de olivo $-1,7$ ha- y matorrales fruto del abandono de la actividad agraria $-0,8$ ha-. Este aspecto ha sido tenido en cuenta al interpretar los datos de estos sectores. En la prospección extensiva el uso del suelo resultó más diversificado, con varios yacimientos ubicados en olivares.

(C) Universidad de Salamanca

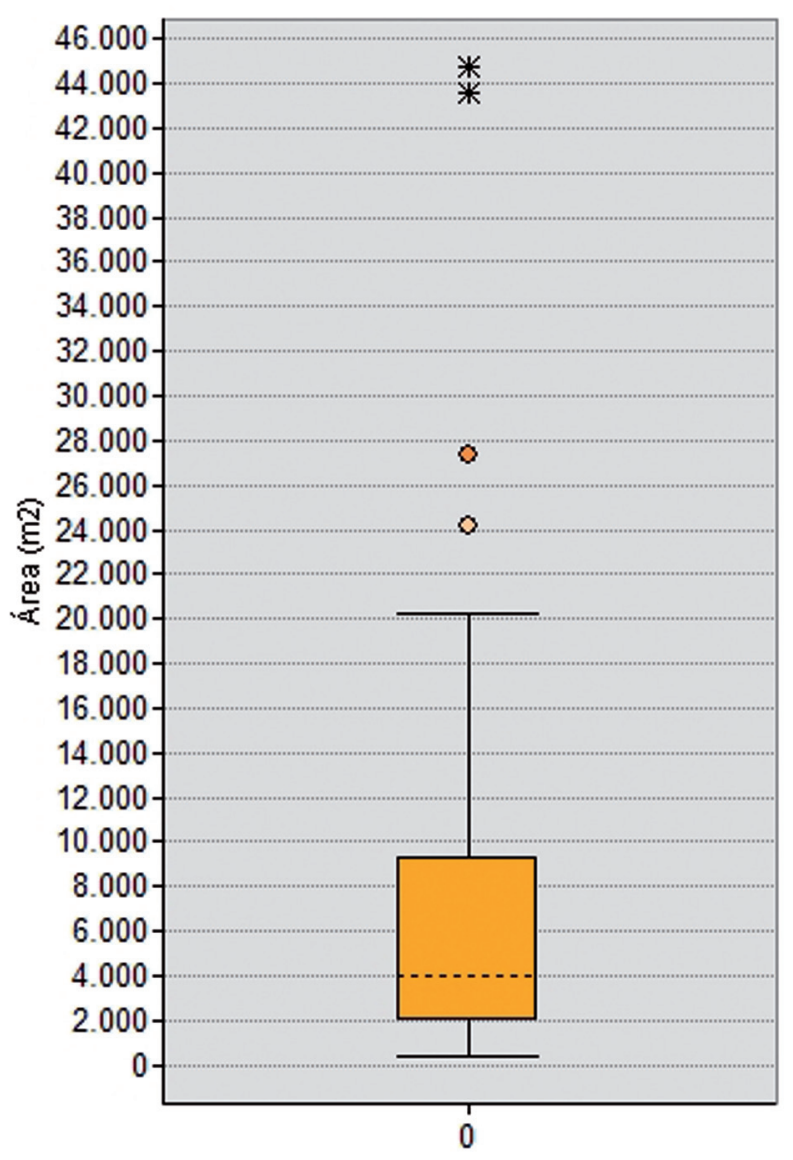

Fig. 2. Diagrama de caja del tamaño de las parcelas prospectadas; las parcelas tienen tamaños muy diversos, si bien el grueso se sitúa alrededor de la $1 / 2 \mathrm{ha}$.

Para la definición de los puntos de asentamiento se tuvo en cuenta la cantidad, densidad y características del material cerámico documentado. Se valoró especialmente la presencia de estructuras in situ, normalmente visibles en los cortes de los aterrazamientos, la presencia de material constructivo -tegula, dolia, estucos y mortero- en el registro superficial, así como la discontinuidad con el resto de áreas prospectadas, definiendo un posible foco independiente aunque las evidencias de estructuras resultaran poco claras.

\subsection{Otras herramientas de análisis del territorio}

Los trabajos de prospección han sido complementados con la excavación de sondeos de diagnóstico en 


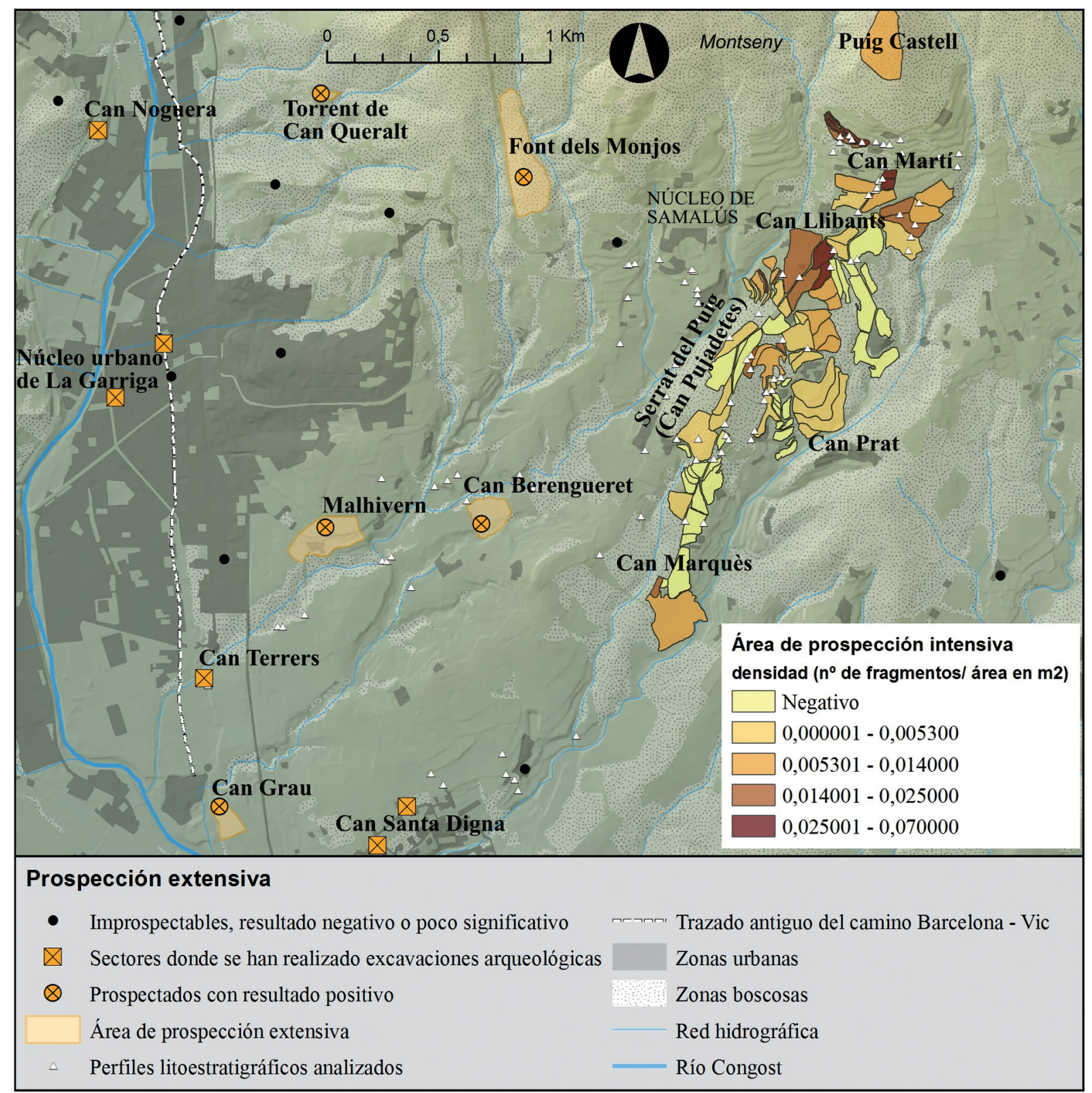

Fig. 3. Área de estudio con la situación de los sectores analizados; a la cartografía de base se han añadido las áreas edificadas y ocupadas por bosques según el Mapa de Cobertes del Sòl de Catalunya elaborado por el Centre de Recerques Ecològica i Aplicacions Forestals-[http://www.creaf.uab.es/mcsc/-].

terrazas agrícolas y el estudio de perfiles litoestratigráficos. Los datos preliminares han permitido empezar a contextualizar los restos arqueológicos dentro de la dinámica sedimentaria del área (García et al., 2012).

El trabajo de campo se ha apoyado en el desarrollo de dos herramientas informáticas: en primer lugar, se ha creado una base de datos utilizando el programa Filemaker, en la que se han recogido los datos de la carta arqueológica ${ }^{12}$ así como las fichas,

12 Se encuentran en el Inventari del Patrimoni Arqueològic de Catalunya (IPAC) del Dept. de Cultura de la Generalitat de Catalunya. 
notas e imágenes tomadas en el campo durante los diversos estudios.

Los elementos de la Base de Datos [BD] están georreferenciados mediante coordenadas de forma que pueden ser conectados al Sistema de Información Geográfica [sIG] del proyecto, realizado con el software ARCGIS 9.3. El SIG incorpora también la cartografía y ortofotografía actuales, modelos digitales de elevaciones, cartografía temática -usos del suelo, hidrografía-, la ortofotografía del vuelo americano de 1956 y distintos mapas antiguos del área de estudio ${ }^{13}$.

Los materiales recogidos en prospección y en el estudio de perfiles se han vinculado a las parcelas y puntos correspondientes a través de estas herramientas. De esta forma, ha sido posible representar sobre el territorio tanto los datos cuantitativos - número de fragmentos y densidad-, como cualitativos -presencia de las diversas producciones-.

\section{Resultados: patrones y dinámica de los asentamientos}

En conjunto se han prospectado de forma extensiva todos los yacimientos que recogía la carta arqueológica entre la vertiente del Montseny y la vía de comunicación histórica que circula paralela al río Congost en los municipios de La Garriga y Cànoves i Samalús (Figs. 3 y 4). En la zona examinada de manera intensiva se han prospectado 92 up's, 54 de las cuales dieron resultado positivo. Se han realizado 3 sondeos en terrazas, y un total de 125 perfiles litoestratigráficos, habiéndose inventariado 5.768 fragmentos de materiales cerámicos.

13 La mayor parte de estos materiales provienen del Institut Cartogràfic de Catalunya (ICC) y su cartoteca, aunque también se han consultado otros archivos (Cartoteca del Centre Excursionista de Catalunya y servicios on line como el Catálogo Colectivo de las Colecciones de Mapas, Planos y Dibujos de los Archivos Estatales y los fondos cartográficos del Instituto Geográfico Nacional).

\subsection{La Antigüedad en el paisaje actual}

La fase antigua ha podido ser identificada en todos los registros gracias a la abundancia del material cerámico ibérico y romano, aparecido en superficie, en los suelos asociados a las terrazas, así como en los perfiles.

Los primeros datos del estudio geomorfológico (García et al., 2012) permiten observar un conjunto de niveles en perfiles en los que aparece material cerámico antiguo de manera exclusiva. Estos niveles son cubiertos por los paquetes de sedimentos que forman la superficie de las terrazas de cultivo actuales ${ }^{14}$, y cubren los restos de suelos anteriores, caracterizados por la presencia de gravas groseras y mal clasificadas con un grado de cimentación variable, denominados caliche (Reeves, 1976). Estos niveles aparecen en ocasiones asociados a restos de estructuras o muros antiguos visibles en algunos de los perfiles o a márgenes en piedra seca de los sistemas de terrazas.

En el sector analizado, los sondeos en las terrazas han permitido identificar que éstas fueron construidas en, como mínimo, dos fases diferentes. La más moderna está claramente asociada a la fase agraria de los ss. XVII-XX. Estos niveles se apoyan en una fase anterior, formada por un paquete sedimentario con presencia exclusiva de material ibérico y romano (García et al., 2012).

14 Hasta aproximadamente $1 \mathrm{~m}$ de profundidad los materiales aparecen mezclados con cerámica moderna (con los vidriados característicos de la cerámica de la zona entre los ss. XVI$\mathrm{xx}$ ). Provisionalmente identificamos los niveles superiores con el suelo de cultivo de los períodos moderno y contemporáneo. 


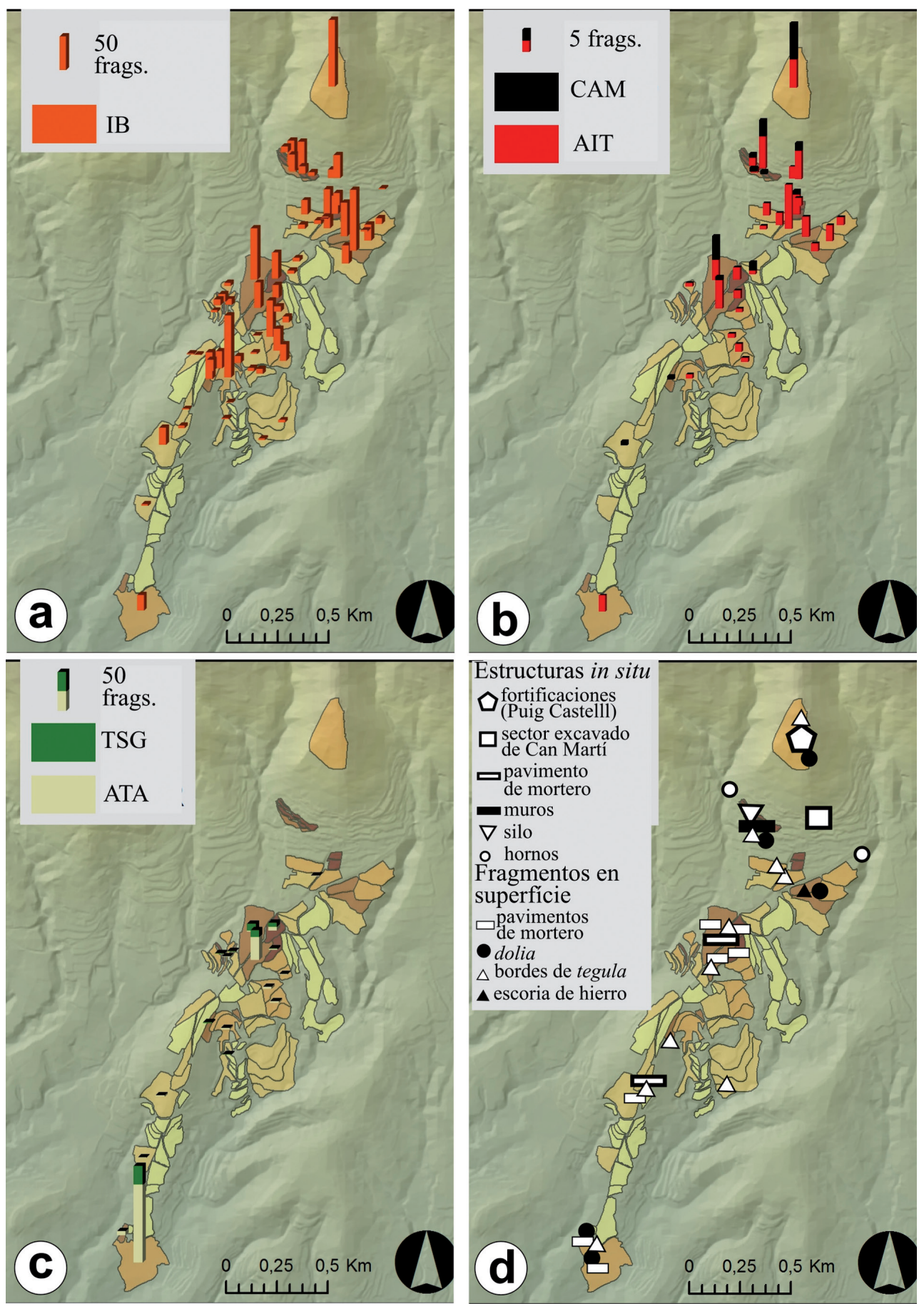

FIG. 5. Distribución de las producciones cerámicas más significativas para estudiar el periodo entre el s. III a. Cy el s. II d. C. en el área de prospección intensiva; se ha añadido el material asociado a los cortes litoestratigráficos: a) producciones ibéricas (comun, paredes finas y ánforas); b) importaciones itálicas asociadas al periodo republicano (barniz negro campaniense y ánforas); c) producciones asociadas al periodo altoimperial (sigillatas y ánforas tarraconenses); d) restos constructivos identificados en los distintos sectores. 
Este contexto arqueológico sugiere que la fase antigua se encuentra integrada en el paisaje actual y forma un substrato importante en su proceso de configuración. Los datos de la prospección que se presentan a continuación reflejan esta situación, permitiendo identificar diversos asentamientos y su contexto cronológico.

La cerámica común es la más abundante en el conjunto del material de superficie, seguida de grandes contenedores -ánforas sobre todo- y finalmente de la cerámica fina de mesa, que representa un porcentaje pequeño, si bien es el más significativo a nivel cronológico. La distribución de las producciones identificadas muestra patrones diferenciables (Figs. 5 y 6$)^{15}$.

\subsection{Periodo ibéricolrepublicano (ss. VI-I a. C.)}

Un primer patrón de asentamiento lo encontramos concentrado en el sector más al $\mathrm{N}$, al pie del cerro de Puig Castell, Cànoves i Samalús. En esta área encontramos abundante cerámica de producción ibérica, con los porcentajes más altos respecto al total de cerámica recogida (Figs. 5 a y 6 ). Por otra parte, destaca la asociación barniz negro campaniense/ánfora itálica (Fig. 5b), poco importante cuantitativamente pero bien representada en un sector donde no aparecen otras importaciones antiguas. Esta situación permite identificar una ocupación que cronológicamente se situaría entre algún momento indeterminado del período ibérico y mediados del s. I a. C.

Los yacimientos asociados a esta ocupación responden a centros relacionados con el poder ibérico y romano (Fig. 5d). En primer lugar, destaca el establecimiento fortificado de Puig Castell, situado en la parte más alta del cerro. Éste es conocido desde por lo menos los años 50 del s. xx (Estrada, 1946-59). El yacimiento fue incluido en las diversas revisiones de la carta arqueológica y prospectado en el marco del proyecto del GIAP-ICAC en 2010. Desde 2011 ha sido objeto de un proyecto que se propone su excavación

15 Los resultados de la prospección descritos a continuación se encuentran en el informe y memoria final depositados en el archivo del "Servei d'Arqueologia de la Generalitat de Catalunya" y en las tesis doctorales de los autores (Flórez, op. cit. n. 6: 196-220 y García, op. cit. n. 6: 194-225). Para un mayor detalle acerca de la caracterización de las tipologías cerámicas remitimos al lector a la consulta de estas publicaciones. en extensión y del que ya han sido publicados los primeros resultados (Guàrdia, 2014, 2015). Los distintos sondeos practicados en el marco de este proyecto proporcionan la oportunidad - no muy habitual- de contrastar estratigráficamente los resultados de las prospecciones de superficie previas.

Así, el buen estado de conservación de las fortificaciones en el $\mathrm{N}$ y E del cerro permitió en la prospección delimitar de forma preliminar, pero con notable precisión, el espacio amurallado, el cual cierra un espacio de unas 4 ha (Fig. 7). También se documentó la presencia de torres y/o bastiones a lo largo de la muralla.

Los resultados de la prospección permitieron definir con bastante claridad la fase de abandono del establecimiento -s. I a. C.-, así como su ocupación en época republicana -ss. II-I a. C.-. Estas cronologías han sido posteriormente corroboradas por los sondeos. La prospección sugirió una cronología de construcción para la mayor parte de la fortificación en la fase ibérica plena -s. IV-III a. C.-, aspecto posteriormente confirmado por las excavaciones arqueológicas (Guàrdia, 2015: 60).

A diferencia del recinto fortificado, el urbanismo interior del establecimiento resultaba prácticamente invisible en superficie. Tampoco pudo observarse la fase inicial -ss. vI-v a. C.-, lo cual resulta lógico al considerar que hasta el momento solo ha aparecido de forma muy testimonial en las excavaciones (Guàrdia, 2015: 58). La prospección de 2010 permitió identificar también una posible fase altomedieval, definida por una torre de planta circular superpuesta al muro antiguo ${ }^{16}$.

En la base del cerro, las estructuras más conocidas corresponden a la conocida como la Villa de Can Martí, descubierta de forma fortuita en los años 50 y reestudiada por un equipo del Museu de Granollers en los 80 (Aquilué y Pardo, 1990) ${ }^{17}$. En este caso se

16 Actualmente se observa una estructura tumular de unos $10 \mathrm{~m}$ de diámetro. En algún punto se puede observar el uso de mortero de cal y la disposición de bloques de tamaño pequeño en forma de opus spicatum. En el relativamente cercano yacimiento ibérico de la Torre Roja de Caldes de Montbui (Fortó et al., 2004) existen los restos de una torre con características bastante parecidas, que se consideran parte de una pequeña fortificación altomedieval (Pladevall, 1991: 317). No documentadas en el registro escrito ninguna de las dos, la interpretación de estas estructuras requeriría de un análisis pormenorizado que supera los objetivos del trabajo.

17 Debe considerarse que el yacimiento no ha sido nunca objeto de una intervención arqueológica propiamente dicha. En los ańos 50, J. Estrada solo pudo contemplar desde 


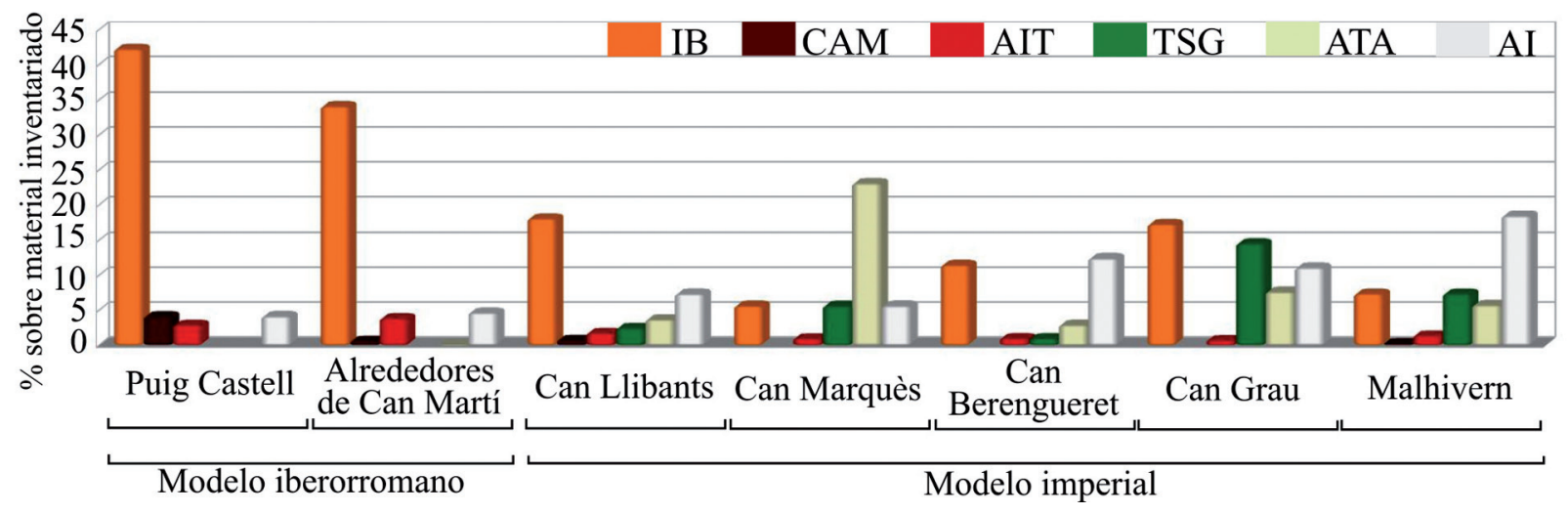

\begin{tabular}{|l|r|c|c|c|c|c|c|}
\hline \multicolumn{1}{|c|}{ Sitio } & Total & $\begin{array}{c}\text { Producciones } \\
\text { ibéricas }\end{array}$ & $\begin{array}{c}\text { Campaniense } \\
\text { A y B }\end{array}$ & Ánfora itálica & $\begin{array}{c}\text { Terra } \\
\text { sigillata }\end{array}$ & $\begin{array}{c}\text { Ánfora } \\
\text { tarraconense }\end{array}$ & $\begin{array}{c}\text { Otras ánforas/ } \\
\text { indeterminadas }\end{array}$ \\
\hline Puig Castell & 244 & 103 & 10 & 7 & 0 & 0 & 10 \\
\hline Alrededores de Can Martí & 1536 & 523 & 9 & 59 & 0 & 1 & 71 \\
\hline Can Llibants & 987 & 178 & 7 & 17 & 24 & 36 & 72 \\
\hline Can Marquès & 429 & 24 & 0 & 4 & 24 & 99 & 24 \\
\hline Can Berengueret & 105 & 12 & 0 & 1 & 1 & 3 & 13 \\
\hline Can Grau & 145 & 25 & 0 & 1 & 21 & 11 & 16 \\
\hline Malhivern & 369 & 27 & 1 & 5 & 27 & 21 & 68 \\
\hline
\end{tabular}

FIG. 6. Distribución de las prospecciones identificadas en distintos asentamientos; en el gráfico se observan los dos modelos de contexto cronocultural detectados en el registro superficial. Se han excluido de la tabla los sectores donde la cantidad de material recogido era inferior a 100 unidades por ser conjuntos poco significativos a nivel cuantitativo.

da la situación inversa a Puig Castell, de forma que la prospección se ha podido contrastar con el resultado de intervenciones anteriores.

Los restos conocidos de este asentamiento se reducen, según la interpretación dada tras la intervención de los 80, a partes de habitaciones pertenecientes a un edificio de planta típicamente itálica. Se habría excavado el tablinum y parte del atrio y de otras dos estancias. La decoración estaba formada por mosaicos de opus signinum y pinturas murales del I Estilo Pompeyano. Esta decoración y el material cerámico localizado permitió a los responsables de su estudio proponer la construcción a finales del s. II a. C. y la destrucción en algún momento de mediados del s. I a. C. Los restos de este asentamiento se relacionaron el exterior los trabajos que supusieron la aparición de las estructuras. En los 80 no se amplió el área de excavación, sino que se documentaron los restos descubiertos y se recuperó y estudió el material de las terreras. El estado actual del yacimiento no permite observar los elementos documentados en los trabajos precedentes. con otros hallazgos puntuales en la zona, tales como restos de hornos, tumbas y muros indeterminados (Gallardo, 1938; Estrada, 1946; Barral, 1978). Estas noticias se han podido contrastar parcialmente ${ }^{18}$.

Por otra parte, las prospecciones han permitido señalar un área de dispersión de material cerámico de hasta unas 20 ha, con algunos indicios de presencia de estructuras antiguas y actividades productivas (Fig. 5d). En conjunto, interpretamos estos yacimientos como lugares de actividad artesanal y/o de almacenamiento asociados a un asentamiento abandonado en el s. I a. C. (Flórez et al., 2013: 195-196).

18 J. Estrada identificó también una posible fase posterior, definida por una serie de tumbas con cubierta de tegulae y una de losas. Actualmente, aunque aparecen algunos fragmentos de tegula en el entorno de los puntos marcados por Estrada, no hay más indicios que confirmen la presencia de estos enterramientos. En parte se podrían vincular a la capilla de Santa Eugenia, sobre la que se ha especulado un posible origen altomedieval, no confirmado por ningún documento (Pladevall, 1991: 67). 


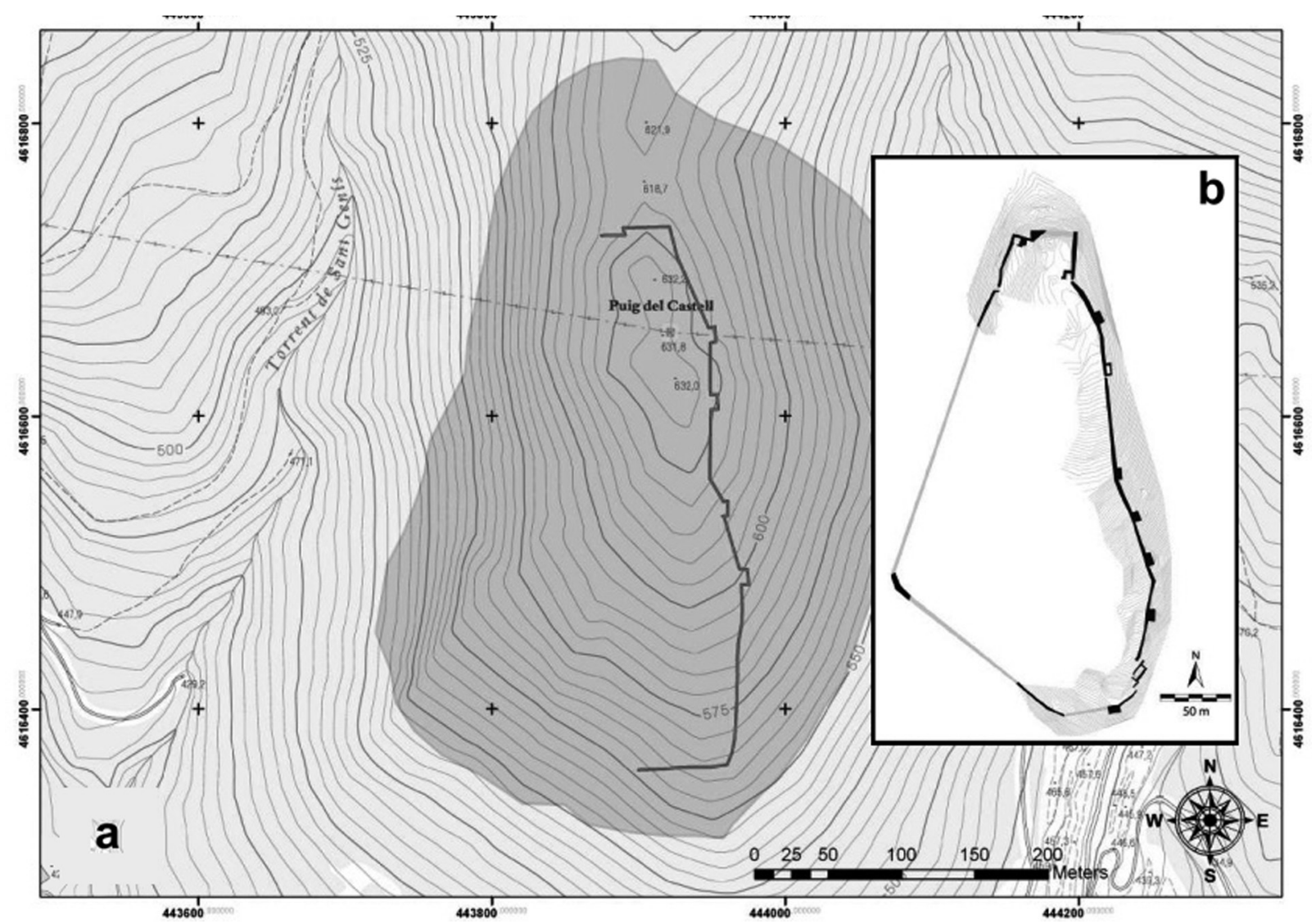

FIG. 7. Recinto fortificado de Puig Castell: a) aproximación obtenida de los datos de prospección con ayuda de un GPS de mano e incluida en el informe inicial de 2010; aunque carece de valor topográfico, la prospección de 2010 permitió definir las características básicas del espa-cio fortificado, confirmadas en buena parte en los sondeos posteriores; b) primera planta topográfica del yacimiento publicada (Guàrdia, 2015: 54).

\subsection{Periodo imperial (ss. I a. C.-III/V d. C.)}

El segundo modelo de poblamiento lo encontramos de forma más sectorizada (Fig. 5c) en algunos puntos concretos a lo largo del área de prospección intensiva $y$, de manera general, también en diversos yacimientos objeto de prospección extensiva, en toda la zona de estudio, desde el curso del río Congost y el antiguo camino real ${ }^{19}$, hasta las terrazas

19 Forma parte de un eje histórico que comunica la costa con el Pirineo -incluyendo la vertiente $\mathrm{N}$ - a través de las cuencas de los ríos Besós y Ter. El recorrido por el área de estudio se encuentra bien documentado en la cartografía del s. XIX y en documentación medieval. Su uso en época romana está también perfectamente establecido gracias a la aparición de miliarios y tramos de vía conservados (Padrós, 2010a; Flórez y Rodà, 2014; Roig, 2015a y b). en las primeras elevaciones de la sierra, al o de Puig Castell ${ }^{20}$ (Figs. 3 y 6).

Las producciones ibéricas e itálicas antes mencionadas aparecen bien documentadas, aunque la cerámica de producción ibérica representa ahora un porcentaje bastante menor. En cambio, destaca la presencia significativa de ánfora tarraconense ${ }^{21}$. En

20 Históricamente han aparecido materiales antiguos en este sector. Esta situación contrasta con los sectores pizarrosos al E de Puig Castell, donde solamente se conocía la existencia de un horno de tipo iberorromano (Raurell, 1994). Actualmente el registro arqueológico del área está formado por restos de explotación forestal de época indeterminada -hornos de cal o resina y carboneras-, aunque hay que atribuirla probablemente a época moderna y contemporánea.

21 Entre las formas identificadas predomina la Dressel 2-4 -22 frags. en total-, seguida de la Pacual $I-5$ frags.-. Existe 
determinadas áreas, estas producciones van acompañadas de un repertorio variado de producciones de terra sigillata (Fig. 6). La presencia de cerámica común de importación africana o itálica no es extraña en estos contextos. En general, predominan las producciones altoimperiales. Las bajoimperiales están también bien representadas en los yacimientos situados cerca de la vía principal, junto al Congost, aspecto que ya había sido detectado por estudios anteriores (Járrega, 1995).

La presencia de estructuras in situ, visibles en superficie en algunos casos e intuidas por la presencia de tegulae o fragmentos de pavimento en otras (Fig. $5 \mathrm{~d})$, permite confirmar la existencia de diversos asentamientos aislados. La interpretación del marco cronológico sería bastante homogénea, detectando un origen al entorno del cambio de era -ss. I a. C./I d. C. - y una fase de ocupación que se alargaría durante el período altoimperial -ss. II o III d. C.- y hasta más adelante en los yacimientos más cercanos a la vía del Congost.

El registro superficial limita el establecimiento de tipologías para este poblamiento ${ }^{22}$, si bien se intuye que no tiene un carácter homogéneo. Se trata de asentamientos de distinto tamaño y complejidad constructiva y funcional. Por otro lado, debe considerarse que son en todos los casos establecimientos de carácter aislado -se presentan como una unidad en el espacio, sin articulación directa entre unos y otrosy con una orientación básicamente productiva. Por otra parte, los elementos de representación aristocrática se documentan de forma limitada y siempre en yacimientos situados en el sector más próximo al río Congost.

un solo fragmento de Layetana/Tarraconense 1 y ninguno de Dressel 1. Este conjunto correspondería, en principio, a todo el período de producción principal de estas ánforas, con cierto predominio de las formas más tardías, es decir, a partir del cambio de era o poco antes (Miró, 1988). Los fragmentos identificables son demasiado escasos para sacar conclusiones, pero concuerdan bien con el período de distribución de las producciones de terra sigillata itálica y sudgálica que aparecen en los mismos contextos.

22 Aun así, propusimos una primera aproximación (Flórez et al., 2013: 189-196) basada en las observaciones realizadas a escala comarcal (Flórez y Palet, 2010). Nos remitimos a estos trabajos para aspectos más concretos sobre las características morfotipológicas que presentan los asentamientos antiguos de la zona.

(C) Universidad de Salamanca

\section{Discusión: dinámicas del poblamiento y estructura territorial alrededor del río Congost (ss. IV a. C.-II d. C.) $)^{23}$}

\subsection{Antecedentes prehistóricos y protohistóricos (hasta mediados del s. II a. C.)}

En el entorno del área de estudio aparecen indicios de poblamiento a lo largo del Neolítico y del Bronce. El registro está formado por restos de estructuras construidas con materiales perecederos y, sobre todo, silos. Los materiales presentes en el relleno de estos sugieren que este tipo de estructura se habría utilizado en distintos momentos entre la Prehistoria y el Alto Medievo ${ }^{24}$.

La construcción de una importante fortificación en el cerro de Puig Castell es determinante en el patrón de asentamiento ibérico en la zona. La prospección superficial permitió catalogarlo como el asentamiento de mayor entidad del sector suroccidental del Montseny. El establecimiento se caracteriza además por la presencia de elementos tipológicos similares a los presentes en los tipos intermedios en la jerarquía de asentamientos ibéricos establecida para la Layetania (Asensio et al., 1998). Esta interpretación parece confirmarse en los resultados de las excavaciones realizadas posteriormente (Guàrdia, 2015: 80).

Por otra parte, la cerámica ibérica aparece de manera abundante en toda la zona prospectada, así como en prácticamente todos los yacimientos de la zona. Ésta aparece asociada a materiales romanos -tardorrepublicanos y/o imperiales- únicamente en determinados casos. La ausencia de material de importación datado con anterioridad a los ss. II y i a. C. representa una dificultad añadida para interpretar el poblamiento de las primeras fases del período ibérico fuera de los núcleos fortificados, más allá de apuntar su probable existencia.

23 El potencial del área de estudio también permite mirar más allá de este momento, tanto hacia el período prehistórico y protohistórico como hacia la etapa bajoimperial y medieval. Nos proponemos desarrollar estas cuestiones en futuros trabajos.

24 El conjunto más destacado se encuentra en Can Santa Digna, publicado muy parcialmente (Alarcos et al., 2006), aunque la carta arqueológica contempla hasta una quincena de puntos con silos de distintos períodos en los municipios vecinos de Samalús. Ejemplos mejor conocidos en la zona occidental del Vallès (Roig y Coll, 2007; Artigues et al., 2007; Carlús et al., 2002, 2008) podrían indicar modelos parecidos. 


\subsection{Los espacios abandonados en el s. I a. C., caracterización de un núcleo de control territorial}

Como hemos visto anteriormente, las producciones itálicas características del período republicano aparecen en dos contextos principales: como residuales en las ocupaciones de época imperial y de forma exclusiva y asociadas a grandes porcentajes de producciones ibéricas en Puig Castell y el entorno de Can Martí (Figs. 5 y 6). A partir de estos datos hemos interpretado una zona de ocupación durante los ss. II-I a. C., situada en el entorno de estos dos sectores, aunque su influencia podría extenderse hacia el sector de Can Llibants y el Serrat del Puig (Fig. 5).

En relación con la cronología, las conclusiones obtenidas por el estudio de Can Martí (Aquilué y Pardo, 1990) parecen continuar siendo válidas ${ }^{25}$. Así, el abandono de las estructuras en esta área en algún momento del s. I a. C. -posiblemente antes de la segunda mitad y seguro antes del 30 a. C.- parece claro y aplicable también al yacimiento de Puig Castell ${ }^{26}$. Al compararlo con la presencia abundante de materiales imperiales en yacimientos vecinos como Can Llibants o el Serrat del Puig, se confirma la hipótesis de que las estructuras más próximas al cerro no estarían en uso en el momento de introducción de producciones como la sigillata itálica o el ánfora tarraconense. A pesar de lo limitado del registro disponible en este momento, el material parece concordar bastante con el que se conoce, por ejemplo, en la ocupación del complejo de Ca l'Arnau-Can Mateu en Cabrera de Mar (García et al., 2000: 33-38), emplazamiento donde encontramos también los mismos tipos de decoración documentados en Can Martí.

Por el contrario, el conocimiento de la cronología inicial de estos asentamientos presenta una mayor dificultad. Considerando que tratamos con materiales

25 Recientemente, V. Cantarellas ha estudiado los materiales de la intervención de los años 80 , llegando a una conclusión similar, si bien señala la ausencia de los tipos tardíos de campaniense в que podrían indicar un momento final anterior a la mitad del s. I a. C. -información facilitada por esta investigadora a quien agradecemos permitirnos añadir el dato en el presente trabajo-.

26 Documentamos las mismas producciones en las prospecciones realizadas en la parte superior e inferior del cerro que las que se documentaron en Can Martí. Como ya hemos comentado, en el caso de Puig Castell los sondeos han confirmado posteriormente la interpretación inicial que dimos a los resultados de la prospección. superficiales o fuera de contexto, el resultado solo puede ser aproximativo. El poblado de Puig Castell estaría ocupado ya en el ibérico antiguo y medio y habría sido objeto de reformas en la fase de los ss. II-I a. C. En cuanto a las habitaciones excavadas en Can Martí no puede confirmarse totalmente la cronología de finales de s. II a. C. propuesta para su construcción, si bien los criterios estilísticos que se han usado permiten establecer un terminus post quem bastante probable $^{27}$. Los materiales aparecidos en la prospección en el resto del sector tampoco contradicen esta posible fecha inicial, e incluso no deberían descartarse ocupaciones anteriores en esta misma área.

A partir de lo expuesto interpretamos que tanto el área fortificada de Puig Castell como Can Martí y los espacios prospectados en su entorno (Fig. 9) habrían tenido una ocupación simultánea en un momento indeterminado situado en un marco cronológico que situaríamos aproximadamente entre 120 a. C. y 30 a. C. como fechas extremas. En este sector documentamos fortificaciones, espacios de representación y actividades productivas. El conjunto que forman las estructuras de la parte alta del cerro -Puig Castell- y del pie de la vertiente -Can Martí- se puede interpretar como un establecimiento con una función más o menos importante relacionada con el control del territorio y de sus recursos. Esta función podría haberse iniciado en Puig Castell en el período ibérico -ss. vi-III a. C.- y, junto a Can Martí, se habría mantenido hasta algún momento desconocido del s. I a. C., adaptándose a los intereses del nuevo poder romano.

En este contexto habría que situar la probable identificación de este sector con la Lauro que aparece en la numismática y en algunos textos antiguos. Tal como se ha planteado en la introducción, hay que vincular este conjunto al contexto cronológico y geográfico en el que aparece este topónimo. Dentro de la estructura territorial vinculada a Lauro, el conjunto de Puig Castell -Can Martí debe considerarse un elemento central, o por lo menos uno de sus núcleos principales-.

27 Los mosaicos de opus signinum y las pinturas del I Estilo Pompeyano han sido documentados en yacimientos bien excavados en Cabrera de Mar (García et al., 2000) y en Can Tacó (Rodrigo et al., 2013), con fechas de construcción en torno al 120 a. C., que podrían marcar su introducción en la península. $\mathrm{Su}$ asociación en un mismo espacio se ha propuesto alguna vez como indicio de antigüedad (Guiral y Mostalac, 1993: 389391), pero también se documentan en contextos posteriores. 


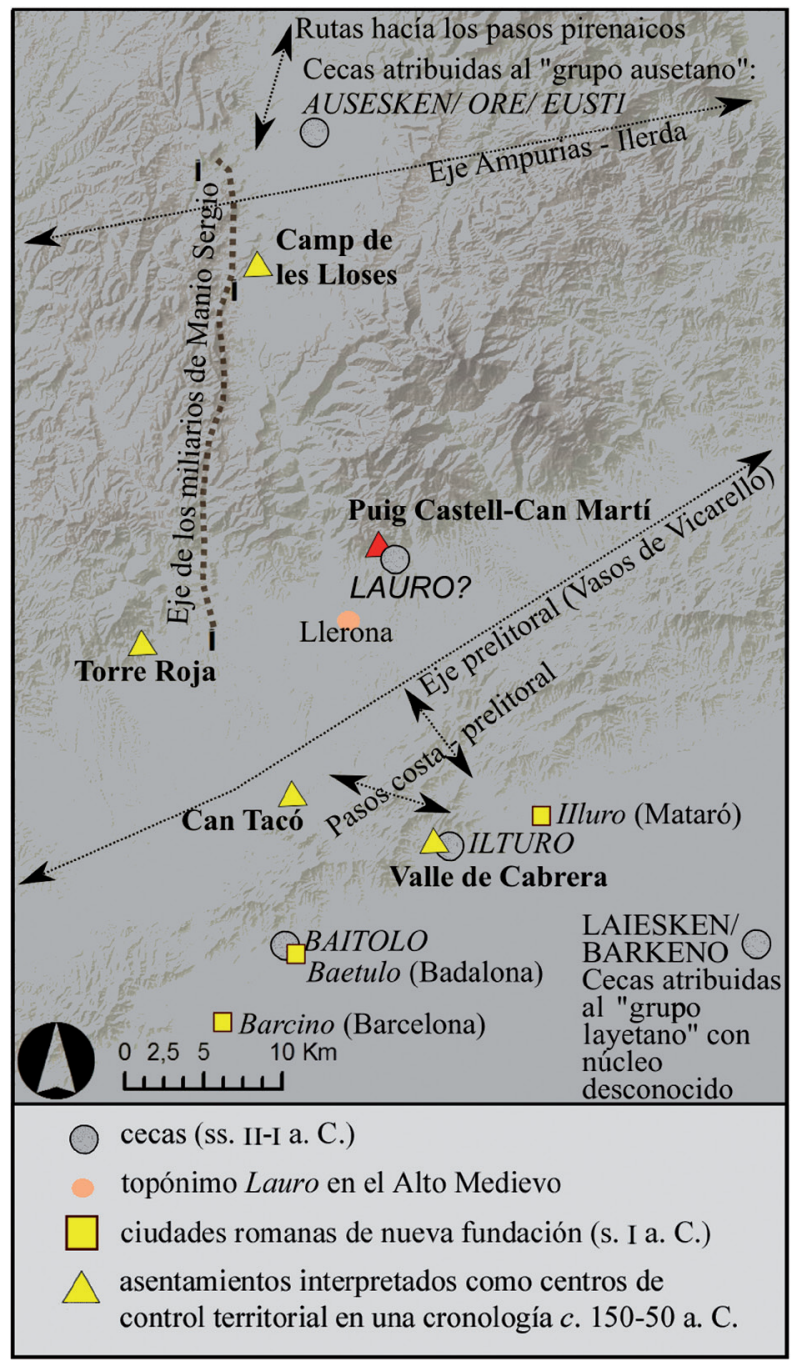

FIG. 8. Situación del conjunto de Puig Castell-Can Martí y de otros sitios relacionados con el control territorial en el eje interior-costa a través del Vallès Oriental en la fase de fin del s. II-s. I a. C.

A nivel cronológico, la fase de los ss. II-I a. C. del sector Puig Castell -Can Martí- conecta con otros yacimientos situados en zonas vecinas que durante los últimos ańos han sido o están todavía en proceso de excavación ${ }^{28}$ (Fig. 8). Se vinculan con un eje de

28 En la costa tendríamos el poblamiento del valle de Cabrera de Mar (Martín, 2002; Zamora, 2012). No hay duda de que este sector ocupa una posición central y claramente superior a nivel jerárquico que el resto de asentamientos layetanos. Más al interior, encontramos los yacimientos de Can Tacó (Mercado et al., 2008; Rodrigo et al., 2013) y Can comunicación interior-costa a través del Vallès adaptado como vía romana hacia 110 a. C. (Fabre et al., 1982: 299; Mayer y Rodà, 1996; Padrós, 2010b: 236-239; Flórez y Rodà, 2014: 242-244). Este itinerario se ha relacionado igualmente con la distribución de hallazgos de monedas de las cecas layetanas, incluyendo entre estas la de Lauro (Sinner, 2013: 178179 y $182-285)$.

Los asentamientos mencionados distan de parecerse formalmente, pero se han interpretado como centros con una función de control territorial en una fase cronológica situada entre 150 a. C. y mediados/ finales del s. I a. C., independientemente de la existencia de fases anteriores ${ }^{29}$ o posteriores ${ }^{30}$. En el periodo que ahora nos ocupa, comparten la estrecha relación entre establecimientos de altura y asentamientos muy próximos de llano, así como la presencia destacada de elementos de la cultura itálica.

Probablemente existiría también un poblamiento de tipo disperso, actualmente poco conocido. Los materiales aparecidos en el sector del Serrat del Puig podrían reflejar una actividad vinculada a los asentamientos del cerro. El yacimiento de la Font dels Monjos, sobre el cual la prospección superficial ha aportado pocos datos ${ }^{31}$, podría ser un caso de ocupación en una zona de vertiente. Igualmente, la carta arqueológica de la zona recoge la presencia de material catalogado como iberorromano en varios silos, que podría indicar su amortización en este período.

Aunque no se han documentado estructuras domésticas concretas vinculadas a este período, la excavación

Massot (Cantarellas, 2014; Cantarellas et al., 2011), situados a $1 \mathrm{~km}$ de distancia uno del otro. Al pie de la sierra prelitoral, se encuentra también el yacimiento de la Torre Roja (Fortó et al., 2004; Fortó y Maese, 2011). En el otro extremo, ya en territorio ausetano, estaría el yacimiento del Camp de Les Lloses (Álvarez et al., 2000; Duran et al., 2008).

29 Solo en el caso del sector de Can Tacó el establecimiento se habría levantado totalmente de nueva planta.

30 En Cabrera y el Camp de les Lloses aparecen posteriormente asentamientos que dan continuidad a la explotación de la zona, pero sin la función de control territorial que habría pasado a municipios romanos próximos de nueva fundación. En el área de estudio, el asentamiento de Can Llibants, situado de forma contigua o quizás superpuesta a los restos de Can Martí, podría cumplir un papel parecido.

31 Los elementos más significativos son fragmentos de ánfora de producción ibérica y púnica, asociados, sin embargo, a fragmentos de tegulae y dolia. En conjunto hay que situar esta ocupación en un momento indeterminado entre los ss. II-I a. C. 
de sondeos en sistemas de terrazas en este sector sugiere la existencia de espacios agrarios de origen antiguo. En este sentido, los materiales cerámicos y las dataciones radiocarbónicas obtenidas proporcionan una cronología situada en torno a los ss. III-II a. C. (Poz44022: 370-155 cal BC) para el paleosuelo sobre el que se asentaron las primeras estructuras agrarias antiguas, que serían posteriores a este horizonte cronológico (García, 2013: 225-230 y 302-303; García et al., $2012)^{32}$. Los resultados sugieren, por tanto, una fase de estos desarrollos de espacios agrarios aterrazados en época romana, cuyo origen podría situarse en el contexto y la dinámica de cambio descrita para la fase de los ss. II a. C.-I d. C.

La dinámica de poblamiento descrita para el área de estudio entre los ss. II a. C. y I d. C. no es un hecho aislado. Debe considerarse una fase, identificada en el registro arqueológico, en la que la organización y explotación de los recursos se estructura a través del poblamiento indígena y de una importante red viaria $^{33}$. Esta organización desaparece en el momento de la creación de núcleos urbanos de nueva planta a lo largo del s. I a. C. Dinámicas similares han sido documentadas en territorios vecinos al área de estudio: en Girona (Burch et al., 2000), Mataró (Olesti, 1995; García et al., 2000), Osona (Padrós, 2010a) o, dentro del área de influencia de Tarragona, en el Penedès (Revilla y Miret, 1995).

\subsection{Una nueva estructuración del territorio a partir del s. I a. $C$.}

Los asentamientos identificados fuera del núcleo de Puig Castell-Can Martí presentan contextos materiales con cronologías situadas en torno al cambio de era. La ocupación de estos yacimientos se extendería más o menos a lo largo del período imperial según cada caso. Sus características indican un poblamiento de tipo disperso que recoge prácticamente toda la variedad de establecimientos rurales de época romana ${ }^{34}$.

32 Cf. también García, op. cit. n. 6: 225-230 y 302-303.

33 El mayor conocimiento de los asentamientos ibéricos en la fase de los ss. II-I a. C. proporciona distintos ejemplos de dinámicas de este tipo (Belarte et al., 2011; Belarte y Plana, 2012).

34 Casi la totalidad de estos estaban incluidos en los inventarios elaborados por J. Estrada (Estrada y Villaronga, 1967; Estrada, 1993). Los resultados de las distintas intervenciones han sido desigualmente publicados: así disponemos
El eje viario paralelo al río Congost es en este momento el eje central de estructuración del territorio. Así, los asentamientos principales por extensión y riqueza de materiales conocidos hasta el momento se encuentran junto o a poca distancia del trazado conocido de esta vía para época medieval y moderna.

En este sentido, el área refleja la introducción de la concepción romano-imperial en todos los aspectos de la organización del territorio extraurbano. Esta dinámica parece no diferir mucho de lo que se conoce en las zonas costeras, donde hay más casos de yacimientos excavados (Plana y Revilla, 2009: 340-344) y de las dinámicas documentadas en el Vallès Oriental en su conjunto (Flórez y Palet, 2010, 2014).

En todos los sectores analizados, aparecen también las producciones cerámicas características de la fase republicana (Fig. 6). En la introducción nos hemos referido a cómo este hecho hizo que buena parte de estos yacimientos se considerasen parte de un poblamiento romano-republicano con origen en el s. II a. C. (Estrada y Villaronga, 1967: 183-184; Estrada, 1993: 56-57). Las excavaciones de los últimos años en Can Terrers y Can Santa Digna permiten conocer algo mejor la dinámica de estos asentamientos. Las estructuras documentadas en estos sitios deben situarse en el s. I d. C., si bien algunos contextos materiales de Can Terrers podrían remitir también a finales del s. I a. C. (Vila et al., 1992: 52). Siguiendo esta dinámica, la cronología republicana de la mayor parte de estos asentamientos debe situarse en su fase más reciente o período final, es decir, a partir de la segunda mitad del s. I a. C.

En cualquier caso, parece evidente que los establecimientos se asientan en zonas previamente explotadas. Las prospecciones intensivas de Samalús, junto con los primeros resultados de los estudios geomorfológicos,

de publicaciones referidas a Granollers (Uscatescu, 2004) o Ca l'Estrada (Fortó et al., 2006), dos asentamientos situados algo al s del área de estudio. Dentro de los límites municipales de la Garriga, Les Franqueses del Vallès y Samalús, pero solo se publicaron algunos resultados de las intervenciones de los ańos 90 en Can Terrers (Vila et al., 1992: 43-52; Pardo y Pàmies, 1998). Para las intervenciones de inicios del s. XXI en Can Santa Digna, Can Noguera, Centro de La Garriga y la misma Can Terrers solo se dispone de los datos recogidos en los informes y memorias técnicas que generaron estas intervenciones y que se encuentran depositadas en el Servei d'Arqueologia de la Generalitat de Catalunya y de los textos incluidos en una monografía local (Roig, 2015a y b; Chorén, 2015; Salvadó, 2015). 


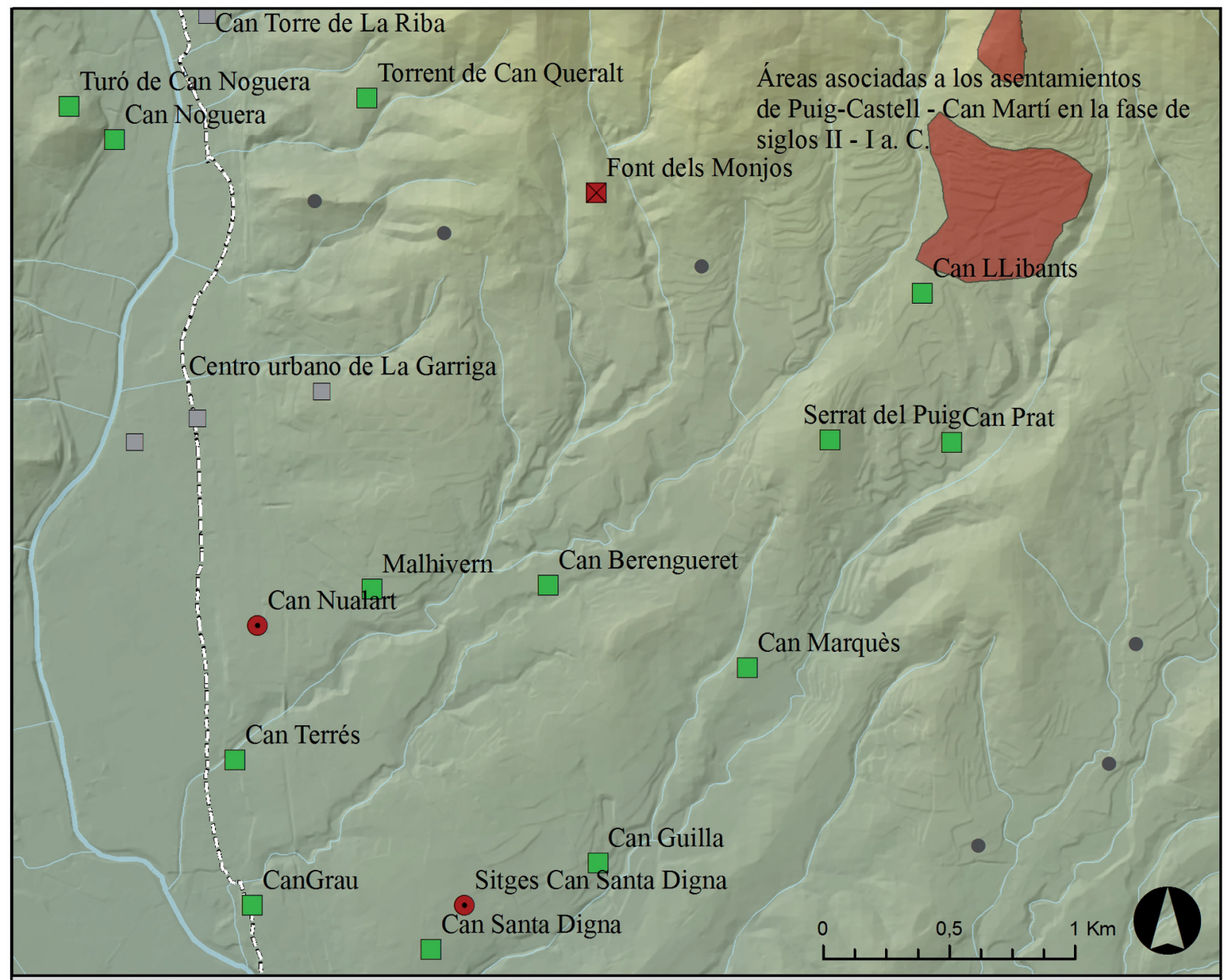

\section{Asentamientos asociados a material romano}

$\boldsymbol{\Delta}$ indicios de abandono

$\square \quad$ indicios de nuevos asentamientos en torno al cambio de era

$\square \quad$ indicios de asentamientos del período imperial con dinámica desconocida

- silos colmatados

- indicios débiles de ocupación antigua

áreas con indicios de abandono

FIG. 9. Interpretación de la dinámica de poblamiento en el s. I a. C. e inicios del s. I d. C. en el área de estudio. 
permiten apreciar que la dispersión del material ibérico, acompañado puntualmente de producciones itálicas del período republicano, es bastante amplia, apareciendo en la mayor parte de los campos prospectados ${ }^{35}$. $\mathrm{Su}$ presencia en los yacimientos prospectados podría situarse en este contexto general. Se trata de un registro de fondo de difícil interpretación, ya que casi siempre los documentamos en posición secundaria, incluyendo restos de edificios posteriores, silos, vertederos o depósitos sedimentarios.

Entre los posibles motivos de esta dispersión está la presencia de estructuras desaparecidas o invisibles en el registro arqueológico analizado, así como restos dispersados por motivos diversos durante los trabajos agrarios.

Por el contrario, las producciones imperiales aparecen bastante concentradas en puntos determinados -incluso dentro de cada campo- y vienen acompañadas siempre de evidencias de estructuras tales como pavimentos, cubiertas de teja o mortero de cal (Fig. 5d). La interpretación de este registro permite su vinculación con espacios de habitación y/o trabajo.

Desde nuestro punto de vista, es posible establecer una secuencia relativa entre la ocupación del entorno de Puig Castell y el resto de asentamientos analizados, los cuales pertenecerían a una etapa posterior. La cronología de cambio de era parece bastante adecuada para situar estos nuevos asentamientos, aunque no debe descartarse un origen algo anterior para como mínimo algunos de ellos ${ }^{36}$. Desde esta perspectiva, el s. I a. C. se muestra como una etapa de transición en el registro analizado en el área de estudio. Esta transición

35 Es importante señalar que, en el área de estudio, la llegada de material de importación itálico a partir de la conquista romana condiciona una mejor identificación arqueológica de esta fase respecto a las anteriores. Como resultado, la representación del período de los ss. II-I a. C. en el registro arqueológico podría aparecer sobredimensionada, especialmente al representarse en forma de puntos sobre el territorio.

36 En este sentido, resulta de especial interés el yacimiento de Ca l'Estrada (Fortó et al., 2006), algo al so del área de estudio pero que también se ha vinculado a un camino tradicional relacionado con la comunicación Vallès-Osona a través de los Cingles de Bertí. En este caso presenta una fase formada por un asentamiento articulado a través de un patio central con una sola fase de ocupación de mediados del s. I a. C. Este edificio amortiza diversas estructuras negativas -incluidos silos- de una fase inmediatamente anterior. Representaría un ejemplo - del que hay otros casos en la comarca (Cantarellas, 2014)- de que la aparición de establecimientos rurales complejos cerca de los llanos aluviales y vías de comunicación tendría precedentes.

(C) Universidad de Salamanca se observa en los cambios en las formas y en el patrón de asentamiento que acabamos de describir (Fig. 9).

Los datos disponibles permiten encuadrar bastante bien estas dinámicas de poblamiento a nivel estructural. Sin duda, deben relacionarse con el establecimiento de nuevos centros urbanos en la costa y su impacto en el interior inmediato.

El aumento del número de asentamientos no parece relacionado con nuevas colonizaciones agrícolas, sino más bien con cambios en la organización de la producción agrícola y la gestión de los excedentes. Podría contribuir a esta imagen la mayor visibilidad en el registro arqueológico de elementos relacionados con la producción, almacenamiento y distribución de productos líquidos, representada en el área de estudio por la abundancia de ánfora tarraconense, dolia y la presencia de pavimentos hidráulicos. Este registro sería a la vez reflejo de la producción de vino lauronense.

Aunque el registro trabajado permite observar los procesos y las dinámicas a nivel estructural, resulta menos adecuado para analizar aspectos más concretos. A nivel cronológico, se puede situar el proceso de transición en un período que comprende desde las guerras sertorianas hasta el principado de Augusto -aproximadamente entre 80 y 30 a. C.-. Si bien parece claro que en época de Augusto ya estaría asentada la nueva estructura territorial, habría que valorar hasta qué punto habrían incidido en el área de estudio los distintos episodios del período tardorrepublicano. Debe señalarse, en este sentido, el interés que podría tener para la historia antigua y la arqueología militar la posibilidad de vincular arqueológicamente la desarticulación del núcleo de Puig Castell-Can Martí con el episodio de la destrucción de Lauro en el contexto de los enfrentamientos entre Sertorio y Pompeyo. Esto permitiría ubicar en el espacio los hechos históricos sobre Lauro mencionados en las fuentes clásicas.

\section{Conclusiones}

Los trabajos del GIAP-ICAC en Samalús se han situado en el entorno geográfico y cronológico del antiguo topónimo de Lauro. Las herramientas de la arqueología del paisaje utilizadas en nuestros estudios nos han permitido desarrollar algunas hipótesis de trabajo basadas en la realidad arqueológica de una zona que ha resultado ser un escenario especialmente 
interesante para estudiar las dinámicas de poblamiento que acompañan el proceso de romanización.

Los datos presentados provienen fundamentalmente del estudio del registro superficial con sus limitaciones, ya que algunos aspectos apuntados solo se podrán confirmar a partir de datos estratigráficos obtenidos en excavaciones en extensión. De todas formas, los trabajos de prospección dentro de una estrategia de estudio del territorio aportan un valor añadido para comprender las dinámicas de asentamiento en una zona concreta. En el caso concreto de los trabajos en la zona de Samalús queremos valorar especialmente el hecho de que la combinación de prospección extensiva e intensiva nos ha permitido trabajar a diferentes escalas. Los datos obtenidos en los distintos niveles de análisis han resultado de gran interés ya que permiten cruzar la dinámica de poblamiento -intra-sitecon la dispersión de materiales superficiales -off-site-, las dinámicas hidrosedimentarias y la evolución del paisaje agrario a lo largo del tiempo.

La Antigüedad -en la que incluimos los períodos ibérico y romano- aparece en todos los registros estudiados como un período importante en la configuración del paisaje. La dinámica arqueológica permite sobre todo aproximarse al momento de transición entre el mundo ibérico y el mundo romano, en un arco que cronológicamente podemos situar entre los ss. III a. C. y iI d. C. En cuanto a la dinámica de los asentamientos se puede observar lo que probablemente sean dos fases en el proceso de integración de un territorio concreto en el contexto político, social y económico romano. Este proceso es paralelo a los movimientos que conducen a la formación del Imperio Romano.

En este sentido, existiría una primera fase que podemos identificar claramente en el sector de Can Martí-Puig Castell, en que parecen mantenerse los puntos claves de la estructura de poblamiento indígena que incorporan elementos de la cultura material itálica. Con los datos actualmente disponibles, se puede plantear la hipótesis de que este sector corresponda a la Lauro de las monedas con leyenda ibérica de finales del s. II a. C. o inicios del I a. C.

A lo largo del s. I a. C. se produciría una transición en el modelo de poblamiento hacia los elementos típicos del poblamiento romano, con la fundación de villae y otros establecimientos rurales de carácter disperso. Los asentamientos principales se desplazan de los alrededores de puntos elevados hasta los principales ejes de comunicación naturales que corresponden en este caso también con los márgenes de un valle aluvial. Esto implica el abandono de las principales estructuras de habitación y representación del sector de Can Martí-Puig Castell, aunque la explotación agrícola de la zona se mantendría a través de nuevos asentamientos.

Estos cambios en el patrón de asentamiento se producirían en el contexto de un territorio en que la explotación agraria es relativamente intensa desde época prehistórica. En este sentido, debería interpretarse el mantenimiento de unos espacios agrarios que son explotados desde distintas estructuras de organización territorial a lo largo del tiempo. En el área estudiada habría que matizar seguramente la idea de una explosión del poblamiento rural o una extensión de la explotación agrícola en época tardorrepublicana. Se trata de una imagen que depende en gran medida de cuestiones relacionadas con el tipo de registro arqueológico de que disponemos y de los procesos de abandono y creación de nuevos asentamientos del s. I a. C. La mención de Plinio a la llamada Lauro Vinícola (Pascual, 1998; Aguilar, 2005) debe situarse en el contexto de la consolidación del nuevo modelo territorial a inicios de la etapa imperial.

A pesar de que los trabajos llevados a cabo nos han permitido profundizar en estas dinámicas, quedan todavía muchos aspectos que desconocemos sobre el funcionamiento y dinámica cronológica de los distintos asentamientos a los que nos hemos referido. Cabe subrayar que podemos afirmar el gran potencial arqueológico del área para profundizar en muchos aspectos de las dinámicas del poblamiento y del paisaje en la Antigüedad, especialmente a partir de estrategias de investigación que tengan en cuenta el conjunto de las estructuras de organización territorial.

\section{Bibliografía}

Aguilar, C. (2005): “Denominació d'origen Lauronensis. El vi del Vallès en època romana”, Lauro, 29, pp. 5-12.

Alarcos, A.; González, R. y Martínez, P. (2006): "Santa Digna III. Un hàbitat del bronze final III al Vallès oriental", Cypsela, 16, pp. 161-175.

Álvarez, R.; Durán, M.; Mestres, I.; Molás, M. D. y Principal, J. (2000): "El jaciment del Camp de les Lloses (Tona, Osona) i el seu taller de metalls". En Ibers. Agricultors, artesans i comerciants. III Reunió sobre economia en el Món Ibèric. Saguntum, Extra, 3. Valencia, pp. 271-281. 
Aquilué, X. y Pardo, J. (1990): “La vil-la romana de Can Martí (Samalús, Vallès Oriental)”, Cypsela, 8, pp. 87-100.

Artigues, P. L.; Bravo, P. e Hinojo, E. (2007): "Excavacions arqueològiques a Can Gambús 2, Sabadell (Vallès occidental)", Tribuna d'Arqueologia, 2006, pp. 111-140.

Asensio, D.; Belarte, M. C.; Sanmartí, J. y Santacana, J. (1998): "Paisatges Ibèrics. Tipus d'assentaments i formes d'ocupació del territori a la costa central de Catalunya durant el periode ibèric Ple". En Congreso Internacional. Los Iberos principes de Occidente. Saguntum Extra, 1. Valencia, pp. 373-386.

Balvey, T. (1931): "Consideracions respecte el Vallès en època romana”, La Gralla, 524, pp. 8-9.

BARral, X. (1978): Les mosaïques romaines et médiévales de la Regio Laietana (Barcelone et ses environs). Barcelona: Instituto de Arqueología y Prehistoria.

Belarte, M. C.; Olmos, P. y Principal, J. (2011): “¿Los romanos 'iberizados'? Aportaciones romanas y tradiciones indígenas en la Hispania Citerior mediterránea", Proceedings of the International Congress of Classic Archaeology (Roma, 2008), Bolletino di Archeologia Online, Volume Speciale, pp. 96-111.

Belarte, M. C. y Plana, R. (eds.) (2012): El paisatge periurbà a la Mediterrània occidental durant la protohistòria i l'antiguitat. Tarragona: ICAC.

Berni, P.; Carreras, C. y Revilla, V. (1998): "Sobre dos nuevos Cornelii del vino tarraconense", Laietania, 11, pp. 111-123.

Burch, J.; Nolla, J. M.; Palahí, Ll.; Sagrera, J.; Sureda, M. y Vivo, D. (2000): "La fundació de Gerunda. Dades noves sobre un procés complex de reorganització d'un territori", Empúries, 52, pp. 11-28.

Cantarellas, V. (2014): "Granges i vil.les d'època tardorepublicana al Vallès Oriental”, Ponències, 18, pp. 15-32.

Cantarellas, V.; Ibars, G.; Castejón, P. y Guitart, J. (2011): "Les ocupacions prehistòriques i la vil.la romana de Can Massot, al terme municipal de Montmeló. Darreres intervencions", Tribuna d'Arqueologia, 20102011, pp. 293-312.

Carlús, X.; lara, C.; López, J.; Oliva, M.; Palomo, A.; Rodríguez, A.; Terrats, N. y Villena, N. (2002): "El paraje arqueológico de Can Roqueta (Sabadell, Vallès Occidental): Diacronía y tipología de las ocupaciones", Bolskan, 19, pp. 121-140.

Carlús, X.; lópez Cachero, F. J.; Terrats, N.; Oliva, M.; Palomo, A. y Rodríguez, A. (2008): "Diacronia durant la prehistòria recent a Can Roqueta (Sabadell-Barberà del Vallès, Vallès Occidental) entre el vi i el I mil.lenni cal ANE", Cypsela, 17, pp. 115-142.

Chorèn, J. (2015): "Vil.la romana de Can Noguera. Segles I-v”. En Barbé, E.; García, A.; Llimargas, J. y Olivé, I.: Història de la Garriga. Dels primers assentaments humans al segle XXI. La Garriga: Ayto. La Garriga, pp. 131-132.
Duran, M.; Mestres, I. y Principal J. (2008): Les Col-leccions de l'exposició permanent del Camp de les Lloses: Tona. Tona: Ayto. Tona.

Estrada, J. (1946-1959): "Fitxer arqueològic", Butlletí de l'Agrupació Excursionista de Granollers, n. ${ }^{\text {os } 30-74 . ~}$

Estrada, J. (1955): Sintesis arqueológica de Granollers y sus alrededores. Granollers.

Estrada, J. (1993): Granollers a l'Antiguitat. Granollers: Tarafa.

Estrada, J. y Villaronga, L. (1967): La Lauro monetal y el hallazgo de Cànoves (Barcelona). Barcelona: Diput. Barcelona.

Fabre, G.; MaYer, M. y RodÀ, I. (1982): "Epigrafia romana d'Osona", Ausa, 102-104, pp. 293-318.

Flórez, M. (2011): Dinàmica dels assentaments $i$ estructuració del territori a la Laietània interior: estudi del Vallès Oriental de l'època ibèrica a l'alta edat mitjana. Tarragona: ICAC- UAB.

Flórez, M. y Palet, J. M. (2010): “Asentamientos rurales y estructuración de la Layetania interior (Barcelona): romanización e impacto de los programas de organización territorial". En Changing landscapes, the impact of Roman towns in the Western Mediterranean. Proceedings International Colloquium, Castelo de Vide, Marvão, 2008. Bolonia: Ante quem., Bolonia: pp. 141-166.

Flórez, M.y PAlet, J. M. (2011): "Estudio arqueomorfológico en un área urbana de la comarca del Vallès (Layetania interior, Barcelona). Aspectos metodológicos", Agri centuriati. International Journal of Landscape Archaeology, 7/ 2010, pp. 255-259.

Flórez, M. y PAlet, J. M. (2012): “Análisis arqueomorfológico y dinámica territorial en el Vallés Oriental (Barcelona) de la Protohistoria (ss. vi-v a. C.) a la alta Edad Media (ss. IX-X)", Archivo Español de Arqueología, 85, pp. 167-192.

Flórez, M. y Palet, J. M. (2014): "Dinámica del poblamiento y romanización en la Laietania interior (Vallès Oriental, Barcelona). Del s. Iv a. C. al s. I a. C.”. En Proceedings of the International Congress of Classic Archaeology (Roma, 2008). Bolletino di Archeologia Online, Volume Speciale. Roma, pp. 59-67.

Flórez, M. y RodÀ, I. (2014): “Las vías romanas en Cataluña: el caso del Vallès Oriental (Barcelona)". En Boube, E.; Bouet, A. y Colleoni, F. (eds.): De Rome à Lugdunum des Convènes. Hommages à Robert Sablayrolles. Supplément, 31. Bordeaux: Édit. Féderation Aquitania, pp. 247-262.

Flórez, M.; Trullén, A. y García, A. (2013): “Aportacions de la prospecció arqueològica a l'estudi diacrònic de les dinàmiques del poblament rural antic al Vallès Oriental (segles v a. C.-v d. C.)". En Prevosti, M.; López, J. y Guitart, J. (eds.): Ager Tarraconensis. 5. Tarragona: ICAC, pp. 183-199.

Fortó, A. y Maese, X. (2011): "La Torre Roja: un jaciment ibèric i medieval (Caldes de Montbui, Vallès Oriental; Sentmenat, Vallès Occidental)", Tribuna d'Arqueologia, 2009-2010, pp. 113-152. 
Fortó, A.; Maese, X.; Pelegero, B.; Pisa, J. y Vidal, A. (2004): "El poblat ibèric de la Torre Roja (Caldes de Montbui-Sentmenat)", Lauro, 26-27, pp. 5-18.

Fortó, A.; Martínez, P. y Muñoz, V. (2006): “Ca l'Estrada (Canovelles, Vallès Oriental): un exemple d'ocupació de la plana vallesana des de la prehistôria a l'alta edat mitjana”, Tribuna d'Arqueologia, 2004, pp. 45-70.

Gallardo, A. (1938): "Del Mogent al pla de la Calma", Butlleti del Centre Excursionista de Catalunya, 518-523, pp. 149-201.

García, A.; Flórez, M.; Lladó, M.; Euba, I.; Palet, J. M. y Giralt, S. (2012): "Human Land Use Strategies in a Mediterranean Mid-Mountain Landscape (Montseny Massif, Barcelona). Analysing Human Landscape Impact through Archaeological and Geomorphological Analysis", eTopoi. Journal for Ancient Studies, 3, pp. 1007-1012.

García, A.; Flórez, M.; Lladó, M.; Palet, J. M. y Giralt, S. (2014): "Una aproximació arqueològica als paisatges del massís del Montseny: resultat de les campanyes de prospecció en espais supraforestals (Matagalls-Pla de la Calma) i del peu del massís (Samalús)". En VIII Trobada d'Estudiosos del Montseny. Barcelona: Diput. Barcelona, pp. 373-382.

García, J.; Martín, A. y Cela, X. (2000): “Nuevas aportaciones sobre la romanización en el territorio de Iluro (Hispania Tarraconensis)", Empúries, 52, pp. 29-54.

Guàrdia, M. (2013): "El jaciment ibèric del Puig del Castell de Samalús”, Vallesos, 5, pp. 136-137.

GuÀrdia, M. (2014): "Repensant Lauro: el projecte de recerca al poblat ibèric del Puig del Castell de Samalús (Cànoves i Samalús)”, Ponències, 18, pp. 75-91.

GuÀrdia, M. (2015): "A les portes de Lauro: el poblat ibèric del Puig del Castell de Samalús (Cànoves i Samalús)", Ponències, 19, pp. 51-86.

Guiral, C. y Mostalac, A. (1993): "Influencias itálicas en los programas decorativos de cubicula y triclinia de época republicana y altoimperial en España: Algunos ejemplos representativos", Espacio, tiempo y forma. Serie I. Prehistoria y Arqueologia, 6, pp. 365-392.

JÁrrega, R. (1995): "Aproximació a l'estudi de l'antiguitat tardana al Vallès Oriental", Limes, 4-5, pp. 63-77.

JÁrrega, R. (2000): "El poblament rural i l'origen de les villae al nord-est d'Hispania durant l'época romana republicana (segles II-I a. C.)", Quaderns de Prehistòria i Arqueologia de Castelló, 21, pp. 271-302.

Konrad, C. F. (1994): Plutarch's Sertorius. London: unc Press Books.

Llorens, M. M. y Ripollès, P. P. (1998): Les encunyacions ibèriques de Lauro. Granollers: Ayto. de Granollers.

Martí, C. (2008): “La seca 'ibèrica' d'Ilturo: historiografia i dades recents. Altres qüestions sobre numismàtica ibèrica del nord-est peninsular", Laietania, 18, pp. 37-76.

Martín, A. (2002): "El conjunt arqueològic de $\mathrm{Ca}$ l'Arnau (Cabrera de Mar, Maresme). Un assentament romanorepublicà', Tribuna d'Arqueologia, 1998-1999, pp. 211-228.
Mayer, M. y RodÀ, I. (1996): "La via romana del Congost", Monografies del Montseny, 11, pp. 93-103.

Mercado, M.; Rodrigo, E.; Flórez, M. y Palet, J. M. (2008): "El castellum de Can Tacó/Turó d'en Roïna (Montmeló-Montornès del Vallès, Vallès Oriental) i el seu entorn territorial", Tribuna d'Arqueologia, 2007-2008, pp. $195-212$.

Miró, J. (1985): "Les fonts escrites i el vi del Conventus Tarraconensis", Pyrenae, 21, pp. 105-112.

Miró, J. (1988): La producción de ánforas romanas en Catalunya. Un estudio sobre el comercio del vino de la Tarraconense (siglos I a. C. - d d. C.). BAR, Int. Ser., 473. Oxford: Archaeopress.

Olestí, O. (1995): "El Territori del Maresme en època republicana (ss. III-I a. C.): estudi d'arqueomorfologia i història", Butlletí de la Societat Catalana d'Estudis Històrics, pp. 135-145.

PADrós, P. (2005): “Algunos ejemplos de la relación existente entre cecas ibéricas y fundaciones tardorrepublicanas en el nordeste de la Hispania Citerior". En Alfaro, C.; Marcos, C. y Otero, P. (coords.): Actas XIII Congreso Internacional de Numismática (Madrid, 2003). Madrid, pp. 523-530.

PADrós, C. (2010a): "Els camins antics i les vies romanes a la comarca d'Osona (Barcelona): Estat de la qüestió", Quaderns de Prehistòria i Arqueologia de Castelló, 28, pp. 233-245.

PADrós, C. (2010b): "El territori de la plana ausetana i el seu entorn des de l'ibèric ple a l'alt imperi”, Cypsela, 18, pp. 243-262.

Panosa, M. I. (2012): Els ibers del Vallès Oriental. Barcelona: L'Abadia de Montserrat.

PArdo, J. (2002): "Josep Estrada, arqueòleg i historiador", Lauro, 22-23, pp. 61-74.

Pardo, J. y PÀmies, A. (1998): "La villa romana de Can Terrés (La Garriga)-Vallès Oriental”. En Mayer, M.; Nolla, J. M. y PARDO, J. (coords.): De les estructures indigenes a l'organització provincial romana de la Hispània citerior: homenatge a Josep Estrada i Garriga. Barcelona: sCEC, pp. 451-460.

Pascual, R. (1998): "La Lauro vinícola". En MaYer, M.; Nolla, J. M. y PARdo, J. (coords.): De les estructures indigenes a l'organització provincial romana de la Hispània citerior: homenatge a Josep Estrada i Garriga. Barcelona: SCEC, pp. 477-484.

Pladevall, A. (dir.) (1991): Catalunya Romànica. XVIII. El Vallès occidental. El Vallès oriental. Barcelona: Enciclopèdia Catalana.

Plana, R. y Revilla, V. (2009): "Les formes de l'habitat rural et les rythmes de l'occupation des campagnes ibériques et romaines dans la zone centrale et septentrionale de la côte catalane". En Actes Colloque AGER VIII. Aquitania, 17. Bordeaux, pp. 333-345.

Raurell, J. (1994): "Breu història sobre els forns de pega", Monografies del Montseny, 9, pp. 181-188. 
Reeves, C. C. (1976): Caliche: origin, classification, morphology and uses. Texas: Estacado Books.

Revilla, V. (2004): "El poblamiento rural en el noreste de Hispania entre los siglos II a. C. y I d. C.: organización y dinámicas culturales y socioeconómicas". En Moret, P. y Chapa, T. (coords.): Torres, atalayas y casas fortificadas: explotación y control del territorio en Hispania (s. III a. de C.-s. I d. de C.). Madrid-Jaén, pp. 175-204.

Revilla, V. y Miret, M. (1995): "El poblament romà al litoral central de Catalunya", Quaderns de Prehistòria $i$ Arqueologia de Castelló, 16, pp. 189-210.

Rodrigo, E.; García Llinares, M. G.; Mercado, M. y Guitart, J. (2013): “El jaciment de Can Tacó (Montmeló i Montornés del Vallés) i els inicis de la presència romana al territori laietà en època republicana”. En Prevosti, M.; López, J. y Guitart, J. (dirs.): Ager Tarraconensis. 5. Tarragona: ICAC, pp. 217-229.

Roig, J. (2015a): "La via romana de la plaça de Can Dachs". En Barbé, E.; García, A.; Llimargas, J. y Olivé, J.: Història de la Garriga. Dels primers assentaments humans al segle XXI. La Garriga: Ayto. La Garriga, pp. 140-142.

RoIG, J. (2015b): "Les restes arqueològiques del nucli urbà de la Garriga: les intervencions a la plaça de Can Dachs i la plaça de l'Església". En Barbé, E.; García, A.; Llimargas, J. y Olivé, J.: Història de la Garriga. Dels primers assentaments humans al segle XXI. La Garriga: Ayto. La Garriga, pp. 125-126.

Roig, J. y Coll, J. M. (2007): "El paratge arqueològic de Can Gambús 1 (Sabadell, Vallès Occidental)", Tribuna d'Arqueologia, 2006, pp. 85-109.

Salvadó, I. (2015): "La vil.la romana de Can Terrers". En Barbé, E.; García, A.; Llimargas, J. y Oliver, J.: Història de la Garriga. Dels primers assentaments humans al segle XXI. La Garriga, pp. 126-129.

Schulten, A. (1937): Fontes Hispaniae Antiquae: Las guerras de 154-72 a. de JC. Barcelona: Librería Bosch.

Sinner, A. G. (2013): "La difusión de las emisiones ibéricas layetanas", Saguntum, 45, pp. 171-192.

Uscatescu, A. (2004): Atles d'arqueologia urbana de Catalunya, volum 1. Granollers. Barcelona: Generalitat de Catalunya.

Vila, L.; Tenas, M. y Oliveras, I. (1992): El patrimoni arqueològic de la Garriga. Sant Cugat del Vallès: Contrapunt.

Villaronga, L. (1960): "Las monedas ibéricas con leyenda LAUro", Nummus, 20-21, pp. 59-67.

ZAmora, D. (2012): "L'espai periurbà de l'oppidum laietà de Burriac. De l'ibèric ple a la romanització". En Belarte, C. y Plana, R. (eds.): El paisatge periurbà a la Mediterrània occidental durant la protohistòria $i$ l'antiguitat. Actes Colloqui Internacional, ICAC, Tarragona, 2009. Tarragona: ICAC. 
